THIAGO MACHADO ARDENGHI

EXPERIÊNCIA E REDUÇÃO DE CÁRIE DENTAL ASSOCIADAS A FATORES SOCIOECONÔMICOS EM CRIANÇAS BRASILEIRAS

São Paulo

2006 


\section{Thiago Machado Ardenghi}

Experiência e redução de cárie dental associadas a fatores socioeconômicos em crianças brasileiras

Tese apresentada à Faculdade de Odontologia da Universidade de São Paulo, para obter o Título de Doutor, pelo Programa de Pós-Graduação em Odontologia.

Área de Concentração: Odontopediatria.

Orientador: Prof. Dr. Marcelo J. S. Bönecker

São Paulo 


\section{FOLHA DE APROVAÇÃO}

Ardenghi TM. Experiência e redução de cárie dental associadas a fatores socioeconômicos em crianças brasileiras [Tese de Doutorado]. São Paulo: Faculdade de Odontologia da USP; 2006.

São Paulo: 12006

1) Prof.(a):

Titulação:

Julgamento:

Assinatura:

2) Prof.(a):

Titulação:

Julgamento:

Assinatura:

3) Prof.(a):

Titulação:

Julgamento:

Assinatura:

4) Prof.(a):

Titulação:

Julgamento:

Assinatura:

5) Prof.(a):

Titulação:

Julgamento: Assinatura: 
Catalogação-na-Publicação

Serviço de Documentação Odontológica

Faculdade de Odontologia da Universidade de São Paulo

Ardenghi, Thiago Machado

Experiência e redução de cárie dental associadas a fatores socioeconômicos em crianças brasieliras / Thiago Machado Ardenghi; orientador Marcelo J. S. Bönecker. -- São Paulo, 2006.

96p. : tab., graf.; $30 \mathrm{~cm}$.

Tese (Doutorado - Programa de Pós-Graduação em Odontologia. Área de Concentração: Odontopediatria) -- Faculdade de Odontologia da Universidade de São Paulo.

1. Cárie dentária - Redução - Fatores sócio-econômicos 2. Cárie dentária (Brasil) 3. Odontopediatria

CDD 617.645

BLACK D631

AUTORIZO A REPRODUÇÃO E DIVULGAÇÃO TOTAL OU PARCIAL DESTE TRABALHO, POR QUALQUER MEIO CONVENCIONAL OU ELETRÔNICO, PARA FINS DE ESTUDO E PESQUISA, DESDE QUE CITADA A FONTE E COMUNICADO AO AUTOR A REFERÊNCIA DA CITAÇÃO.

São Paulo,

Assinatura:

E-mail: 


\section{DEDICATÓRIA}

À minha familia, por permitirem que este sonbo se realizasse:

Minha mãe, meu pai, minha avó e meus irmãos, que, mesmo longe, sempre estiveram presentes. Obrigado pelo incentivo e por fazerem parte da minha vida. Sem vocês nada estaria completo! 


\section{AGRADECIMENTOS}

Apenas palavras não serão suficientes para expressar a gratidão que tenho por um número enorme de pessoas que, mesmo indiretamente, contribuíram para o desfecho deste ciclo da minha vida . Mesmo assim, sei que muitos de vocês não serão citados, talvez por um momentâneo lapso de memória, ou talvez por serem tão importantes que fica difícil descrevê-los. Desde já: Obrigado!

A Deus, por estar presente todos os dias de minha vida:

"A minha alma te segue de perto; a tua destra me sustenta."

Salmo 63:8.

Ao meu orientador Prof. Dr. Marcelo Bönecker

Por toda a orientação na realização deste trabalho e também no meu crescimento como aluno. Muito mais do que um professor, tu sempre foste um grande exemplo de dedicação, perseverança e responsabilidade para mim; um amigo que sempre estará meu coração e de quem sentirei muita falta. Obrigado por teres acreditado em mim, apesar de mim mesmo! 


\section{À Raquel}

Menina dos meus olhos, por quem meu coração sempre bate mais forte. Obrigado por todo o amor, compreensão e principalmente paciência no dia-a-dia quando nem eu mesmo consigo me entender.

$$
\begin{aligned}
& \text { "Te amo sem saber como, nem quando, nem onde, } \\
& \text { te amo diretamente, sem problemas, nem orgulbo: } \\
& \text { assim te amo porque não sei amar de outra maneira" } \\
& \text { (Pablo Neruda) }
\end{aligned}
$$

\section{À querida Prof ${ }^{a}$. Dr ${ }^{a}$. Célia Regina Martins Delgado Rodrigues}

Um Ser Humano formidável! Por todo o apoio e incentivo desde o início e em todos os momentos em que deixei de acreditar que era possível. Obrigado por estar sempre presente!

\section{Ao querido amigo Prof. Dr. José Carlos Petrossi Imparato}

Se eu pudesse reduzir em algumas palavras o que dizer de ti, certamente uma delas seria "gratidão". Obrigado pelo imenso incentivo, oportunidades e amizade. Tu sabes o quanto foste, és e sempre serás importante para mim. Porque idéias, sonhos e palavras se tornam concretas quando permitimos compartilhá-las!

\section{Ao Prof. Dr. Antônio Carlos Guedes-Pinto}

Pelos conselhos e experiência de vida repassados em todos os momentos de trabalho e de descontração. Obrigado por todo o incentivo e principalmente pelas palavras de confiança que o Sr transmite quando conversamos. E também por toda a hospitalidade aqui em São Paulo.

A Prof ${ }^{a}$. Dr ${ }^{a}$ Maria Ercília de Araújo, por toda a ajuda neste trabalho e principalmente pelas oportunidades no Departamento de Odontologia Social. Obrigado pela sua amizade e confiança! 
Ao Prof. Dr. Antônio Carlos Frias pela disponibilidade na coleta dos dados de CPOD, e ao Prof Dr. Leopoldo Jose Ferreira Antunes, pela pronta-atenção em ajudar nas minhas dúvidas de estatística. Muito obrigado!

Ao colega Celso Zilbovicius e a Paula Brolezi de Souza, por toda a ajuda indispensável na coleta dos dados socioeconômicos.

Ao Prof. Dr Fausto Medeiros Mendes, meu grande amigo e irmão. Tu és uma daquelas pessoas difíceis de passarem despercebidas na vida dos que te conhecem. Obrigado por compartilhar tua amizade não só nas inúmeras discussões científicas (inclusive a do navio!), mas também em todos os momentos de descontração, risadas e cervejas! E também por teres participado diretamente da realização deste estudo.

Às minhas queridas amigas e colegas de curso e trabalho Luciana Butini Oliveira e Monique Saveriano De Benedetto, por todos os momentos que passamos juntos compartilhando vitórias e situações difíceis. Sentirei muita saudade dos dias em Araras, das viagens hilariantes nas voltas para São Paulo, das "reuniões"com os alunos, e principalmente de vocês me lembrando de tudo que eu (sempre) esqueço!

Aos meus colegas de Doutorado: Marize, Fernanda, Luciana Sanglard, Alessanda, Ricardo, Francisco, Sandra, e todos os colegas de Pós-Graduação, por todos os momentos de descontração e estudo compartilhados.

Aos professores do Departamento de Ortodontia e Odontopediatria: Prof ${ }^{\mathbf{a}}$. Márcia Wanderley, Prof ${ }^{a}$. Ana Lídia Ciamponi, Prof ${ }^{a}$. Ana Estela Hadad, Prof ${ }^{a}$. Dr ${ }^{a}$. Célia Regina MD Rodrigues, Prof ${ }^{a}$. Dra . Maria Salete NP Corrêa, Prof Dr Antônio Carlos Guedes- 
Pinto, Prof. Dr. Fausto Medeiros Mendes e Prof ${ }^{a}$. Dr ${ }^{a}$. Claudia Perez Trindade, pelos ensinamentos, mesmo que muitas vezes não retribuídos da mesma forma com que foram passados. Obrigado!

A todos os funcionários do Departamento de Ortodontia e Odontopediatria da FOUSP-SP: Marize, Júlio, Clemência, Fátima, Thais, Nalva, Viviane, Édna, Ronaldo e Edílsson. Pelo respeito e "galhos quebrados" durante estes anos.

A todos os meus amigos e, em especial ao colega Luciano Casagrande, por compartilhar momentos alegres, mas também científicos que proporcionaram histórias inesquecíveis!

"Colorado, colorado, nada vai nos separar"!

A todos os professores do curso de Odontologia do Centro Universitário Hermínio Ometto, e a todos os meus alunos, por compreenderem todos os momentos de ausência. Obrigado por me permitirem o maior prazer da minha vida: ser professor.

A todos os funcionários da biblioteca que ajudaram na formatação desta dissertação.

À cidade de São Paulo: Céu, chão e estrela do "todo" e suas partes: pela vontade de não te deixar!

À CAPES pela bolsa de doutorado. 
Ardenghi TM. Experiência e redução de cárie dental associadas a fatores socioeconômicos em crianças brasileiras [Tese de Doutorado]. São Paulo: Faculdade de Odontologia da USP; 2006.

\section{RESUMO}

Objetivos. Avaliar a associação entre experiência de cárie dental com fatores socioeconômicos e a influência desses fatores na redução dos índices de cárie em crianças de 12 anos de idade nas capitais brasileiras. Métodos. Dados oficiais sobre a experiência de cárie dental (CPO-D) em cada município foram reunidos a partir dos resultados de levantamentos epidemiológicos a respeito de saúde bucal realizados em âmbito nacional nos anos de 1996 e 2002-2003. Dados censitários e provenientes de publicações governamentais a respeito dos indicadores socioeconômicos foram associados à experiência de cárie em 2002-2003, e ao percentual de redução nos índices CPO-D entre 1996 e 2002-2003 utilizando-se análise de regressão linear múltipla. Resultado. Análise de regressão linear simples indicou associação significante entre experiência de cárie e diferentes indicadores socioeconômicos. Resultados da análise de regressão linear múltipla revelaram que menor experiência de cárie esteve associada positivamente ao índice de desenvolvimento humano do município (IDH) e renda per capita. Capitais com menores desigualdades na distribuição de renda (Coeficiente de Gini), menores índices de CPO-D e maior porcentagem de crianças livres de cárie em 2002-2003 apresentaram maiores níveis de redução de cárie. Conclusão. Municípios com

melhores perfis socioeconômicos apresentaram uma menor experiência de cárie dental indicando que estratégias públicas de saúde devem ser direcionadas para esses determinantes. Os resultados também sugerem que redução de cárie dental 
demanda ações governamentais amplas que busquem diminuir as ineqüidades socioeconômicas.

Palavras-Chave: Cárie dentária - Socioeconômico - Prevalência - Crianças Redução - Brasil. 
Ardenghi TM. Dental caries experience and reduction associated with socioeconomic indicators in Brazilian children [Tese de Doutorado]. São Paulo: Faculdade de Odontologia da USP; 2006.

\section{ABSTRACT}

Objectives. Investigate the association between dental caries and socioeconomic indicators in 12-years-old children from Brazilian capitals. Assess the influence of these socioeconomic indicators to dental caries decrease in this population between 1996 and 2003 Methods. Dental caries experience was estimated by gathering data on DMFT index supplied by two country-wide surveys performed in 1996 and 20022003. Measurements of socioeconomic status at city-level used census data and official publications. Association between socioeconomic status with dental caries experience in 2002-2003 and percentage of reduction in DMFT indexes between 1996 and 2002-2003 were fitted using multiple linear regression analysis. Results. Simple linear regression analysis indicated significant associations between DMFT and different socioeconomic factors. Results from multiple linear regression analysis showed that a lower DMFT index was associated with higher values of human development index (HDI) and income. Capitals with lower levels of income inequalities, lowers values of DMFT and highest percentage of caries-free children in 2002-2003, presented highest percentage of DMFT reduction between 1996 and 2002-2003. Conclusions. Capitals with lower socioeconomic status presented highest levels of dental caries than better-off capitals, indicating that public health strategies should target these determinants. The results also suggest that improvements in dental caries experience demand broad governments actions to reduce socioeconomic inequalities.

Key Words: Dental caries - Socioeconomic - DMFT - Children - Reduction - Brazil. 


\section{SUMÁRIO}

p.

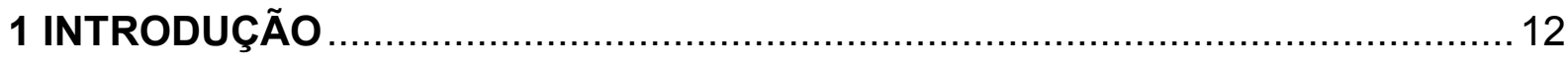

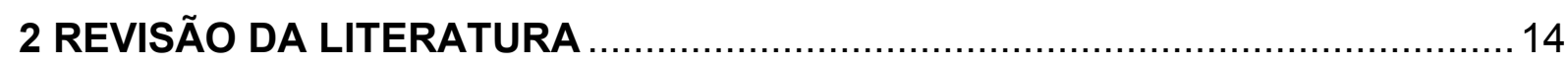

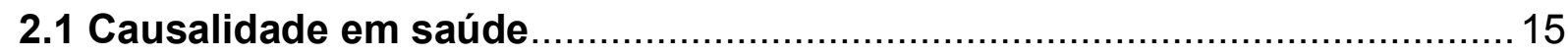

2.2 Determinantes socioeconômicos em saúde bucal .................................. 24

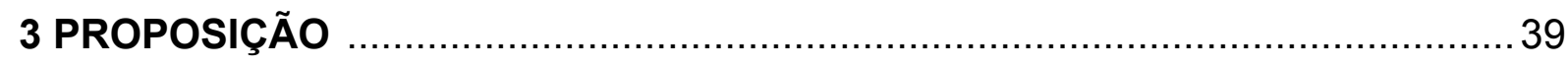

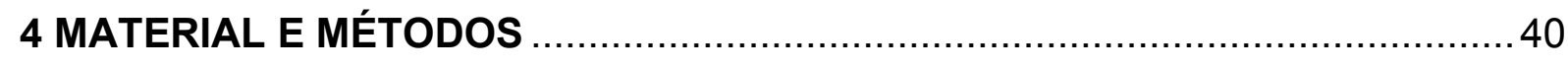

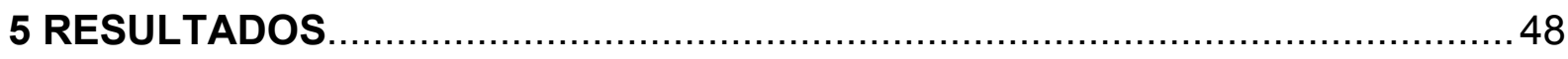

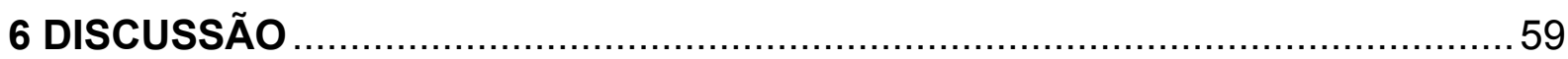

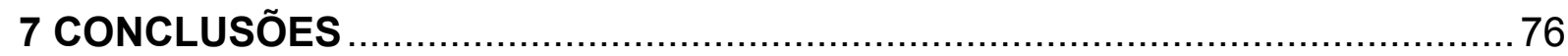

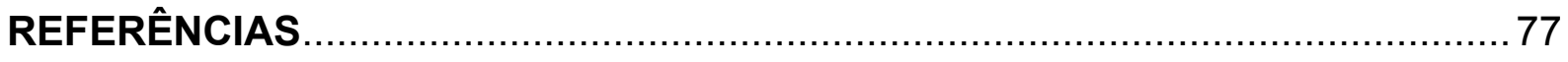

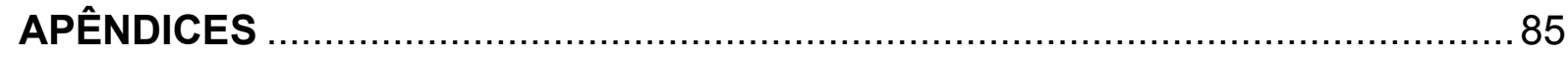




\section{INTRODUÇÃO}

O conhecimento e identificação dos determinantes que influenciam o estado de saúde de uma população é um dos requisitos básicos para a aplicação de medidas efetivas de promoção e controle de um determinado agravo. Diferenças no estado de saúde não podem ser inteiramente explicadas por serviços assistenciais, carga genética ou fatores individuais. Em termos gerais, tanto entre sociedades, como no nível individual, desigualdades socioeconômicas tendem a ser os principais determinantes do processo saúde-doença.

A influência desses determinantes se conjuga em situações de exclusão social, privação de bens e serviços essenciais ao desenvolvimento humano, marginalização e reduzido capital social, menor acesso a serviços básicos de saúde e aumento significativo no risco de grande parte das doenças crônicas, contextualizando-se tanto no nível individual, como no âmbito coletivo.

A constatação dessa concepção ecossocial do processo saúde-doença impulsionou a mudança do paradigma de um modelo biomédico baseado exclusivamente nos fatores de risco individuais para uma abordagem direcionada aos fatores contextuais e macro-sociais a que uma população está exposta. Estudos direcionados ao conhecimento de tais fenômenos e associação têm sido o foco de grande parte da comunidade científica.

Essas mudanças também puderam ser notadas na ciência odontológica, resultando em um aumento expressivo do número de publicações relacionando o impacto dos fatores macro-contextuais nos parâmetros de saúde bucal, principalmente considerando cárie dental como desfecho. 
Nas últimas décadas pôde-se notar uma melhora efetiva nos quadros de saúde bucal da população, refletindo-se em diminuição da prevalência de cárie demonstrada em inúmeros artigos científicos. Porém embora essa afirmativa traga um certo conforto, essa doença ainda afeta uma grande parte da população mundial, impactando significantemente os aspectos fisiológicos e a qualidade de vida dos indivíduos afetados.

No Brasil, desde a década de 1980, levantamentos epidemiológicos têm sido realizados em âmbito nacional para avaliar tendências em termos de saúde bucal na população. Uma análise comparativa dos resultados de tais levantamentos permite afirmar que, em crianças de 12 anos de idade, houve diminuição tanto em termos de prevalência quanto de severidade de cárie dental, sendo esse valor desigualmente distribuído em diferentes regiões nacionais. Entretanto, poucos estudos foram conduzidos com a proposta de avaliar os fatores associados a essa redução.

A realização desses estudos não implica simplesmente o conhecimento dos níveis da doença ou fatores a que uma comunidade está exposta, mas também o oferecimento de dados que servem de base para planejamento e implementação de medidas governamentais de acordo com as necessidades da população estudada. 


\section{REVISÃO DA LITERATURA}

Para que este estudo pudesse ser justificado, realizou-se uma revisão literária de determinados tópicos que, embora alguns não estejam envolvidos diretamente com o assunto abordado, facilitam o entendimento da pesquisa proposta.

Primeiramente foi realizado um breve comentário a respeito da evolução dos conceitos de causalidade e de como esses conceitos influenciaram os paradigmas de atuação na questão causal. A importância desse conhecimento não se refere simplesmente a um referencial histórico e filosófico, mas também porque implica o entendimento de modelos explicativos dos determinantes do processo saúdedoença, seus mecanismos e níveis de atuação, o que permite a implementação de estratégias de atuação voltadas a esses determinantes.

$\mathrm{Na}$ segunda sessão deste capítulo, procurou-se discutir a respeito da influência dos determinantes socioeconômicos na saúde bucal, tendo como enfoque principal o desfecho considerado neste estudo - cárie dental. Também foi objetivo dessa sessão abordar acerca dos critérios metodológicos utilizados na estratificação social da população, em se tratando de estudos direcionados à saúde bucal. 


\subsection{Causalidade em saúde}

Determinados eventos tendem a seguir outros em um período de tempo. Em certas situações, observações nos permitem afirmar que o aparecimento de um evento é sucedido por determinada causa ou etiologia particular. O entendimento dessa "cadeia causal" é um dos principais objetivos da epidemiologia, ou seja, identificar as causas de um determinado agravo e os fatores relacionados com o seu desenvolvimento, bem como a distribuição da doença em termos de tempo, espaço e população afetada (ALMEIDA-FILHO; ROUQUAYROL, 2002; GORDIS, 2004).

Particularmente na odontologia, a ocorrência de agravos à saúde é um fenômeno que suscita grande interesse por parte da comunidade científica na medida em que contribui de maneira substancial para o desenvolvimento e implementação de ações de prevenção, tratamento e controle (NADANOVSKY; LUIZ; COSTA, 2005). Tal fenômeno tem sido freqüentemente estudado através de procedimentos metodológicos baseados em modelos estatísticos direcionados à identificação de associações entre determinantes e seus efeitos na saúde bucal da população (DALY et al., 2002; GORDIS, 2004; NADANOVSKY; LUIZ; COSTA, 2005).

Genericamente, pode-se contextualizar o estudo da causalidade por meio de modelos teóricos e paradigmas que se tornaram clássicos pela diversidade de abordagem da questão entre causa e efeito (MOYSÉS; MOYSÉS, 2006; NADANOVSKY; LUIZ; COSTA, 2005).

O conhecimento desses referenciais teóricos torna-se importante na medida em que possibilita um entendimento mais acurado do desenvolvimento histórico da 
epidemiologia, bem como as visões e debates a respeito dos conceitos e práticas atuais de atuação no processo saúde-doença, tanto do ponto de vista genérico como específico a respeito de saúde bucal.

Entretanto, os conceitos atuais de causalidade sofreram reformulações ao longo da história, sendo que o estudo do tema possui referenciais históricos mesmo antes das grandes descobertas microbiológicas como, por exemplo, as referências encontradas na Bíblia a respeito dos conceitos de contágio da Lepra (ALMEIDAFILHO; ROUQUAYROL, 2002; EVANS, 1993; MACMAHON; PUGH, 1970).

mesmo se pode afirmar no que se refere à participação dos fatores ambientais e sociais como determinantes de saúde. O conhecido estudo de Hipócrates -“Águas, ares e lugares”- já abordava o efeito significativo das condições de vida na ocorrência de doenças (BOING; KOVALESKI; ANTUNES, 2006; PEARCE, 2005). Mas foi notoriamente com o advento da Revolução Industrial e seu impacto nas condições de vida dos trabalhadores que a saúde passou a ser compreendida como desfecho associado a parâmetros sociais, fato esse expresso nos estudos de Louis-René Villerme e Rudolf Virchow (BOING; KOVALESKI; ANTUNES, 2006; BUCK et al., 1989).

Porém, até meados do século XIX, o paradigma dominante a respeito do processo saúde-doença na população era a teoria dos "miasmas", constituídos por inúmeros seres ou organismos invisíveis com poder de reprodução e que emanavam do solo, águas ou materiais em putrefação (BUCK et al., 1989; CAMERON; JONES, 1983; GORDIS, 2004; SUSSER; SUSSER, 1996a). Tal teoria ganhou maior credibilidade posteriormente a partir do notório trabalho de William Farr, o qual implementou o uso de classificações diagnósticas específicas para estatísticas de 
mortalidade, ampliando a utilização dos eventos vitais para pesquisa em saúde (MOYSÉS; MOYSÉS, 2006).

De acordo com Susser e Susser (1996a), a teoria dos miasmas pode ser interpretada como uma das perspectivas para o entendimento da ação do meio como determinante de saúde e, embora equivocada como modelo de explicação causal, seus representantes demonstraram onde e como conduzir a busca por explicações causais, além de introduzirem estratégias sanitárias importantes que trouxeram grandes avanços nos quadros de saúde.

O paradigma dos miasmas perdurou como modo de explicação causal até o advento da microbiologia e parasitologia (ALMEIDA-FILHO; ROUQUAYROL, 2002; PEARCE, 2005; SUSSER; SUSSER, 1996a). Porém, mesmo antes da descoberta das bactérias, técnicas epidemiológicas eram utilizadas para o estabelecimento da relação causal e/ou método de transmissão das epidemias (PEARCE, 2005). A partir do momento em que se identificava a fonte responsável pela doença, ou por sua transmissão, a epidemia poderia ser prevenida sem o verdadeiro agente causal ter sido caracterizado e isolado corretamente. Entretanto, as diretrizes para o estabelecimento de uma relação causal e a idéia de causa e efeito de uma doença nem sempre eram corretamente estabelecidas (EVANS, 1993; GORDIS, 2004; KHOURY et al., 2004; SUSSER; SUSSER, 1996a).

Assim, durante a chamada "Era pré-bacteriológica" (EVANS, 1993), uma série de estudos epidemiológicos clássicos surgiram com intuito de discutir as bases da relação causal e o controle de determinadas epidemias. Exemplos referem-se aos achados de James Lind em 1757 a respeito do desenvolvimento do escorbuto e sua relação com a deficiência de frutas cítricas, e os estudos de John Snow em 1854 a respeito do modo de transmissão da cólera através da água de abastecimento 
contaminada de um ponto de captação do rio Tâmisa, o que levou ao surgimento da legislação para a filtragem da água em 1857 (EVANS, 1993; GORDIS, 2004; MACMAHON; PUGH, 1970).

Com a introdução da bactéria na lista dos microrganismos patogênicos em 1850, inicia-se uma nova maneira de explicação causal, surgindo então a "Era bacteriológica" com a teoria dos germes (BUCK et al., 1989; SUSSER; SUSSER, 1996a). As principais contribuições dessa época referem-se a Henle, Klebs e Koch, pois seus achados foram relevantes para o desenvolvimento dos postulados de causalidade de Henle-Koch; além das descobertas microbiológicas de Pasteur em 1865.

O pensamento vigente na época era de que a grande maioria das doenças poderiam ser explicadas de acordo com essa teoria, fundamentada basicamente na unicausalidade. Ao mesmo tempo, a epidemiologia baseada nas condições do meio e no dinamismo social, derivada da teoria dos miasmas, é substituída pelo foco de ação no controle dos agentes infecciosos (SUSSER; SUSSER, 1996a).

Entretanto, já nas primeiras décadas do século $X X$, verificou-se que nem todas as doenças infecciosas seguiam os postulados de Henle-Koch. Com a crescente importância das doenças não-infecciosas no cenário epidemiológico ao longo do século XX, as limitações dos postulados de Henle-Koch tornavam-se cada vez mais evidentes. O conceito de unicausalidade não poderia mais ser aplicado a todas as epidemias. Desta maneira, com o reconhecimento das doenças crônicas de causas, muitas vezes não totalmente reconhecidas, o ambiente social passou novamente a ser considerado como possibilidade explicativa nos modelos causais (MOYSÉS; MOYSÉS, 2006). 
Segue-se, então, a percepção da multicausalidade, em que diferentes fatores podem estar relacionados direta ou indiretamente com um efeito de acordo com uma "rede de causalidade" (MAcMAHON; PUGH, 1970).

A concepção dessa multifatorialidade pressupõe que, para a ocorrência de uma doença, é necessário um conjunto de causas que precedem o evento (ROTHMAN; GREENLAND, 2005). Neste contexto, deve-se considerar ainda uma discussão pertinente no que diz respeito às diferentes abordagens que tentam fundamentar as diretrizes para a existência de uma inferência causal e não meramente estatística.

Tais diretrizes para a validação de uma associação causal foram descritas primeiramente pelos critérios de Hill em 1965 (HILL, 1965). De acordo com o autor, para que uma associação fosse determinada "causal", nove critérios ou "view-points" deveriam ser considerados: 1 - força de associação, 2 - consistência, 3 temporalidade, 4 - especificidade, 5 - gradiente biológico ou dose-resposta,6 plausabilidade, 7 - coerência, 8 - experimentação e 9 - analogia.

Tais critérios têm sido revisados ao longo dos anos, principalmente porque nem todos conseguem ser completamente preenchidos. Muitos dos critérios de Hill acabam se sobrepondo e nem sempre devem ser aplicados em todas as circunstâncias (THYGENSEN; ANDERSEN; ANDERSEN, 2005).

Dessa maneira, com exceção à temporalidade, estes critérios não podem ser vistos como uma regra ou condição sine qua non para julgar uma associação causal, (THYGENSEN; ANDERSEN; ANDERSEN, 2005).

Outra abordagem de multicausalidade foi proposta por Rothman (1976). De acordo com o autor, um conjunto de causas componentes é necessário para a ocorrência de uma doença. Tais componentes podem ser causas "necessárias" 
(causa componente que tem que estar presente para se produzir a doença) ou "suficientes" (conjunto mínimo de causas componentes que, quando presentes, levam ao desenvolvimento de doença) (GORDIS, 2004; NADANOVSKY; LUIZ; COSTA, 2005; ROTHMAN; GREENLAND, 2005).

De acordo com essa abordagem, a identificação de todas as causas componentes de uma determinada causa suficiente não é fundamental se o objetivo é a prevenção da doença (ROTHMAN; GREENLAND, 2005). Algumas implicações e concepções deste modelo podem ser destacadas como a multicausalidade na percepção do processo de doença e a interação entre as diferentes causas componentes.

Cabe ressaltar que, de acordo com Rothman e Greenland (2005), embora não haja um critério absoluto para verificar a validade científica de uma associação causal, é possível verificar a validade dos resultados obtidos em um estudo. Assim, o julgamento final a respeito de uma inferência causal freqüentemente dependerá do acúmulo de evidências a partir de uma série de estudos, cabendo ao pesquisador discutir as possíveis hipóteses e analisar os possíveis erros decorrentes do estudo.

Tão importante quanto o entendimento dos modelos de abordagem da questão causal previamente descritos, é a contribuição da epidemiologia na construção de modelos explicativos voltados à representação dos fatores etiológicos de uma determinada doença. Esses modelos buscam a compreensão das interrelações envolvidas entre os diferentes fatores relacionados ao processo saúdedoença, seus níveis de atuação e possibilidades concretas de intervenções preventivas e/ou curativas em um determinado agravo (NADANOVSKY; LUIZ; COSTA, 2005). 
Em meados do século XX, um dos modelos que se tornou bastante popular foi o modelo ecológico, segundo o qual a saúde seria o resultado dinâmico entre o indivíduo ou população e o ambiente no qual ele se insere (NADANOVSKY; LUIZ, COSTA, 2005). A concepção do modelo é baseada em uma tríade composta pelo hospedeiro, o meio e o agente, como pode ser visualizado em termos de cárie dental pela figura 2.1 adaptada de Keyes (1962) (KEYES, 1962; NADANOVSKY; LUIZ; COSTA, 2005).

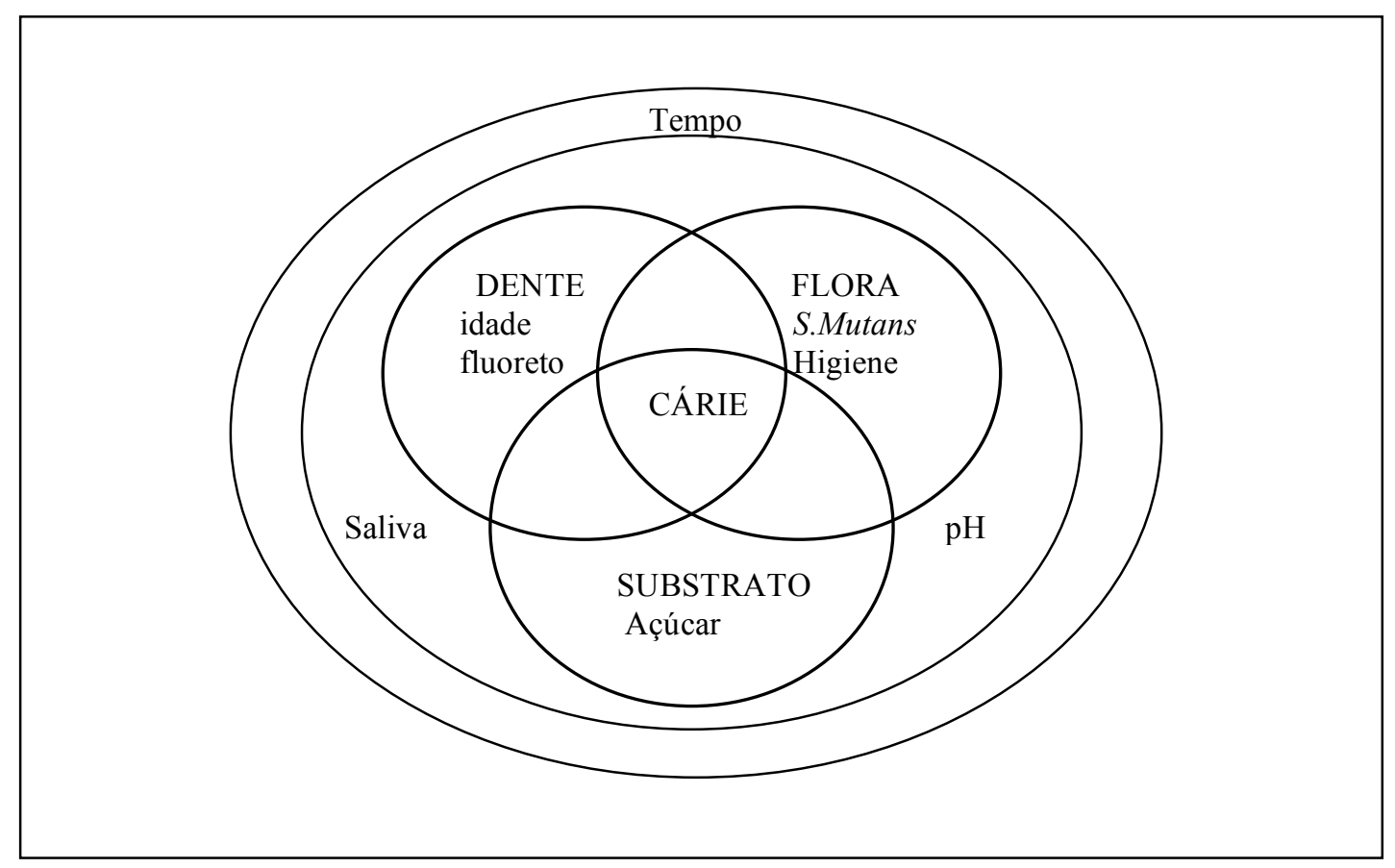

Figura 2.1 - Exemplo de modelo ecológico para cárie dental (Adaptado de KEYES, 1962)

Apesar de esse modelo demonstrar uma relação causal entre "hospedeiromicrobiota-substrato" e cárie dentária, atualmente o conceito de cárie pode ser definido como processo mais complexo, no qual, tanto a presença de microrganismos capazes de produzir ácido através de um substrato favorável, como a presença de um hospedeiro susceptível são considerados fatores necessários, mas não suficientes para o desenvolvimento da doença. 
Dessa maneira, novos modelos baseados em concepções multifatoriais foram propostos, dentre eles a chamada "rede de causas", como descrito anteriormente (MAcMAHON; PUGH, 1970).

Críticas a esse modelo referem-se primordialmente à não-identificação dos verdadeiros mecanismos que levam à construção da "teia", bem como a característica não-hierárquica na análise dos fatores de risco, ou seja, uma intervenção de saúde em um determinado fator de risco levaria à diminuição na incidência da doença, independente de seu posicionamento na rede, se proximal ou distal (KRIEGER, 1999; NADANOVSKY; LUIZ; COSTA, 2005).

Além disso, Krieger (1999) relata que nesse modelo há uma ênfase maior nos fatores biológicos, sendo os fatores sociais secundários na explicação da doença. Do mesmo modo, não há uma diferenciação clara entre os determinantes individuais e populacionais, não distinguindo as "causas dos casos individuais" das "causas de incidência na população" (MOYSÉS; MOYSÉS, 2006; ROSE, 1985).

A concepção da influência da sociedade como determinante de saúde e sua inter-relação e interdependência com fatores endógenos e relativos ao indivíduo, tem influenciado mais diretamente a possível explicação etiológica das doenças, dentre elas a cárie dental (MOYSÉS; RODRIGUES, 2004). Assim, o modelo "sistêmico" proposto por Dahlgren e Whitehead (1992) baseia-se na premissa de que as causas das doenças estão em diferentes sistemas de organização desde fatores individuais até a estrutura social (Figura 2.2) (DALY et al., 2002; MOYSÉS; RODRIGUES, 2004; NADANOVSKY; LUIZ; COSTA, 2005). 


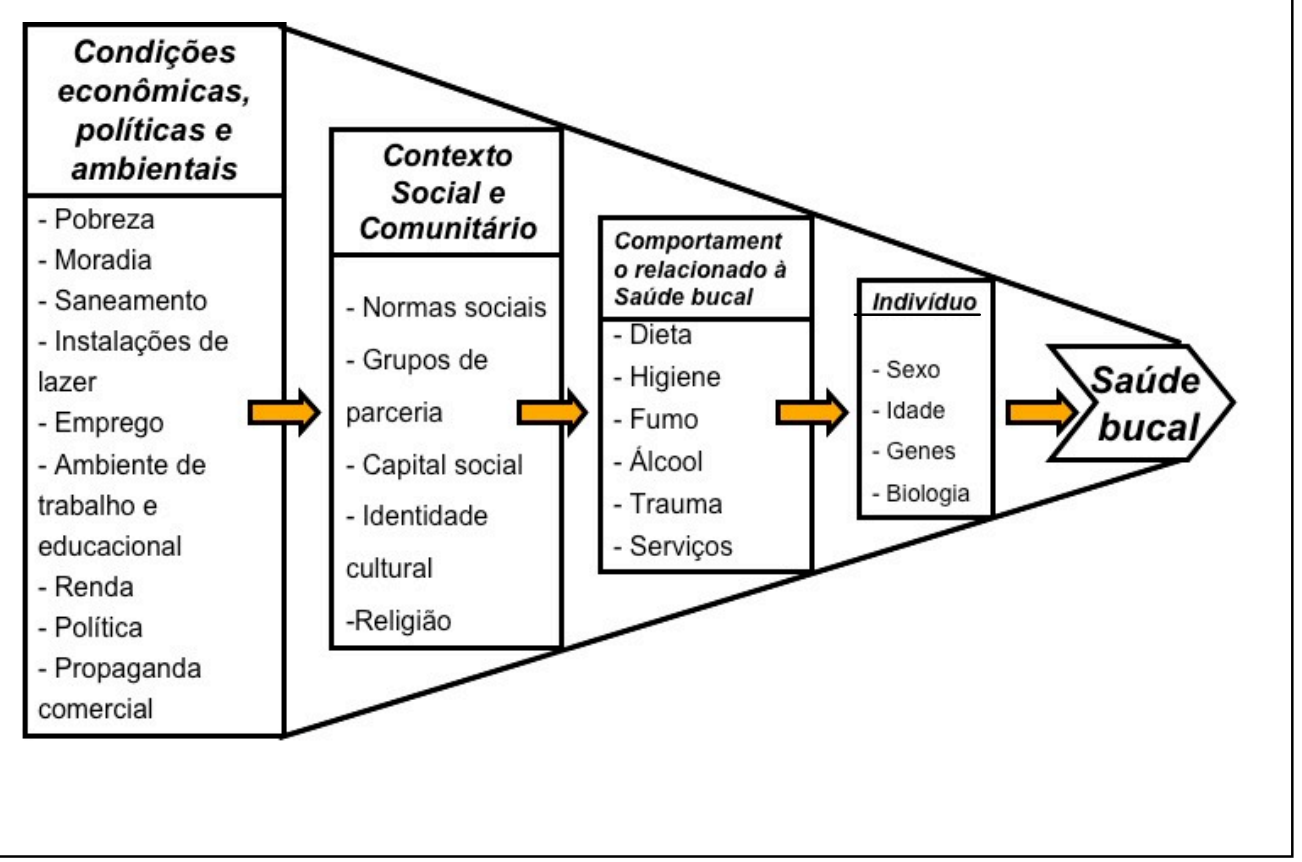

Figura 2.2 - Exemplo de modelo sistêmico adaptada à saúde bucal (Adaptado de DALY et al.,2002)

De acordo com esse modelo, cada nível influencia e é influenciado pelos demais. Tal modelo, além de induzir a uma estruturação hierárquica entre os níveis de atuação das causas (NADANOVSKY; LUIZ; COSTA, 2005), possibilita uma visualização mais holística do processo saúde-doença na medida em que explica como os fatores individuais estão correlacionados com o suporte social e comunitário (MOYSÉS; RODRIGUES, 2004).

Nessa perspectiva, o modelo permite uma análise dos reais determinantes da saúde e dos níveis nos quais as estratégias de promoção de saúde e controle das doenças terão maior efeito, sendo que o efeito dos determinantes mais distais (como os macrofatores sociais) tem sido o principal foco de atenção nas pesquisas de saúde bucal (ANTUNES; TRIGUEIRO; TERRA, 1999). 


\subsection{Determinantes socioeconômicos em saúde bucal}

Independente do paradigma vigente no que se refere à abordagem no mecanismo causal, uma das grandes dificuldades enfrentadas em saúde pública refere-se ao conhecimento dos fatores que explicam a variação nos níveis de saúde encontrados em diferentes populações (DALY et al., 2002; HOBDELL et al., 2003). A resposta para essa simples questão, embora complexa de formular, torna-se crucial no melhor entendimento do caráter etiológico de uma doença e no desenvolvimento de políticas públicas voltadas à diminuição das desigualdades em saúde (HOBDELL et al., 2003; MOYSÉS; MOYSÉS, 2006; ROSE, 1993; WAGSTAFF, 2002).

Diversos estudos têm demonstrado que as desigualdades nos níveis de saúde podem ser em grande parte explicadas por diferenças nos indicadores socioeconômicos às quais uma pessoa ou população está exposta (ANTUNES et al., 2006; BRAVEMAN et al., 2005; ELLWOOD; O'MULLANE, 1996; GRATRIX; HOLLOWAY, 1994; LOCKER; FORD, 1996; MACKENBACH et al., 1997; MARCENES; SHEIHAM, 1992; MUIRHEAD; MARCENES, 2004; MULLER, 2002; WAGSTAFF; VAN DOORSLAER, 2000; WILKINSON, 1997a).

Essas diferenças podem afetar a saúde durante o ciclo de vida dos indivíduos, contextualizando-se em diferentes níveis, sob diferentes vertentes etiológicas, determinando vulnerabilidade, exposição ou efeitos psicológicos e interagindo com outros fatores como raça, sexo e demais condições historicamente associadas à exclusão social (BRAVEMAN et al., 2005).

A influência dos parâmetros sociais acaba sendo marcante nos níveis de saúde de uma comunidade (ANTUNES, 2005). Disparidades de ordem 
socioeconômicas são indicativos de uma comunidade com reduzido capital social, menor acesso aos serviços básicos de saúde, capacidade restrita de cooperação, solidariedade, reciprocidade entre seus membros e de reduzir o impacto prejudicial das doenças sobre a coletividade (BOING; KOVALESKI; ANTUNES, 2006; BRAVEMAN et al., 2005; MACKENBACH, 2002; MOYSÉS; MOYSÉS, 2006; PATTUSSI et al., 2001; WAGSTAFF, 2002). Mesmo entre membros de uma sociedade, o hiato existente entre ricos e pobres influencia de maneira substancial os níveis de saúde bucal, ou seja, a extensão das ineqüidades e relativa pobreza determina substancialmente o processo de saúde-doença (LOCKER, 2000; PATTUSSI et al., 2001; WAGSTAFF, 2002; WILKINSON, 1997a).

Do mesmo modo, parece existir um gradiente socioeconômico em saúde, estendendo-se em toda a escala social e não apenas na linha de corte da pobreza, sendo que a área e o contexto de vida adquirem uma importância fundamental nos níveis de saúde (KRIEGER, 2001; MOYSÉS; MOYSÉS, 2006).

Nesse contexto, saúde e problemas socioeconômicos devem ser encarados como fenômenos inter-relacionados (ROSE, 1993). Populações mais pobres tendem a apresentar piores níveis de saúde e um risco multiplicado de danos a esta, tanto em nível de indivíduos afetados como também em termos globais na população (WAGSTAFF, 2002). Tal relação coexiste em uma série de indicadores de saúde, incluindo os de saúde bucal (LOCKER, 2000).

Essa afirmativa se torna verdadeiramente válida em se tratando de cárie dental, principalmente quando as diferenças nos níveis desta doença são mensuradas tendo a população como unidade de análise (AMSTUTZ; ROZIER, 1995; ANTUNES et al., 2002, 2003, 2006; BALDANI; NARVAI; ANTUNES, 2002; 
HOBDELL et al., 2003; LOCKER, 2000; NADANOVSKY; SHEIHAM, 1995; NEWTON; BOWER, 2005; PATTUSSI et al., 2001; PERES et al., 2003).

De acordo com Petersen (2006), as correlações encontradas entre os determinantes sociais e saúde, quando analisadas em termos de saúde bucal, sugerem que as circunstâncias impostas pela sociedade em termos de acesso e escolhas individuais em saúde têm um papel primordial tanto na prevalência como na severidade de cárie dental.

Desse modo, torna-se necessário situar os processos que envolvem a saúde bucal dentro de um amplo cenário político, econômico e cultural e não simplesmente como a soma de atitudes e comportamentos individuais (NEWTON; BOWER, 2005). O modo de como se dá a organização social de uma população, as condições de vida e trabalho, bem como a alocação de recursos e a política econômica, têm seus efeitos no processo de saúde e doença da população (MOYSÉS, 2000; WAGSTAFF, 2002), pois agem como "pano de fundo" na escolha por opções saudáveis (BURT, 2005).

A constatação do impacto do meio social na saúde bucal tem sido alvo freqüente dos estudos epidemiológicos na área odontológica. Tal fato pode ser vislumbrado considerando o aumento significativo no número de pesquisas ressaltando a relação existente entre cárie dental e fatores de ordem social, econômica e comportamental (ANTUNES; TRIGUEIRO; TERRA, 1999; ANTUNES et al., 2003; MARCENES; SHEIHAM, 1992; MUIRHEAD; MARCENES, 2004; NEWTON; BOWER, 2005; PATTUSSI et al., 2001; PATTUSSI; HARDY; SHEIHAM, 2006; PERES et al., 2003; SANDERS et al., 2006; WATT; SHEIHAM, 1999).

Essa afirmação corrobora com Burt (2005), o qual relata que: “após anos de identificação e quantificação de fatores biológicos, os pesquisadores se tornaram 
conscientes de que há mais na doença do que meramente a biologia". Sociedade e saúde não podem jamais ser encaradas sobre dois prismas distintos (ROSE, 1993), pois mudanças na sociedade têm seus efeitos agindo diretamente nos níveis de saúde e doença apresentados pela população (MARCENES; BÖNECKER, 2000; NADANOVSKY; SHEIHAM, 1995; NEWTON; BOWER, 2005; PATTUSSI; HARDY; SHEIHAM, 2006; PETERSEN, 2005).

A grande preocupação que redirecionou muitos pesquisadores ao estudo de determinantes sociais relacionados com o desenvolvimento de doença se respalda na principal questão que ainda persiste na Odontologia: "Por que alguns grupos populacionais possuem maior probabilidade de desenvolvimento de cárie?". De acordo com a literatura, a simples variação nos fatores biológicos não é parâmetro suficiente per si para responder a essa questão (BURT, 2005; HAUSEN, 1997).

A identificação de macrofatores como fatores socioeconômicos torna-se um parâmetro extremamente útil na identificação de populações de risco, além de ser economicamente mais viável (HAUSEN, 1997; KUMAR; WADHAWAN, 2002), principalmente considerando que abordagens redirecionadas para população e não somente para o indivíduo, têm maior efetividade (ROSE, 1993) na redução da incidência de cárie. Além disso, tem sido demonstrado que tais fatores são determinantes importantes associados ao declínio evidente na prevalência de cárie dentária durante as últimas décadas (NADANOVSKY; SHEIHAM, 1995; NARVAI et al., 2006).

Há uma extensa literatura abordando as inter-relações entre determinantes socioeconômicos e saúde bucal, sendo que a maioria dessas pesquisas consiste na utilização de diferentes modelos estatísticos visando a elucidar a relativa força de 
associação entre cada variável socioeconômica e a ocorrência de cárie dental, considerando tanto o indivíduo como a população como unidade de análise.

Entretanto, de acordo com Newton e Bower (2005), muitas dessas pesquisas têm sido limitadas pela ausência de modelos teóricos que consigam refletir a complexidade dos processos reais da vida social, bem como os mecanismos causais que conectam a estrutura social com o processo saúde-doença. A ausência de tal modelo faz com que os determinantes sociais sejam tratados como fatores de risco isolados, com mínima apreciação de como esses fatores se inter-relacionam no tempo e lugar e, fazendo parte da vida social, influenciam a saúde bucal (MOYSÉS; MOYSÉS, 2006).

Diversas teorias têm sido propostas para explicar como os determinantes socioeconômicos influenciam na saúde (LOCKER, 2000). Dentre essas teorias, a teoria materialista e a psicossocial têm sido amplamente discutidas na literatura (MOYSÉS, 2000; SANDERS et al., 2006). A primeira delas refere-se à influência dos níveis absolutos de privação e sua relação com o processo saúde-doença. Ou seja, a renda maior, por exemplo, possibilitaria, além de um maior acesso aos serviços de saúde, uma série de condições favoráveis ao indivíduo para que ele tome decisões saudáveis. As desigualdades em saúde nesse contexto ocorreriam porque grupos sociais de baixa renda são expostos a um contexto de vida propício à doenças (MOYSÉS, 2000). Por outro lado, o argumento psicossocial tem ênfase maior na maneira em que as pessoas classificam seu estado social em comparação com os outros membros da sociedade (SANDERS et al., 2006).

Sanders et al. (2006) reforçam a discussão do tema e revelam que a posição socioeconômica relativa pode influenciar mais fortemente a saúde do que os indicadores absolutos de privação material em indivíduos com maiores vantagens 
sociais, sendo que, em grupos de desvantagens sociais, situados na porção inferior da escala social, a situação é inversa.

Entretanto, a literatura não é concisa no que se refere a que teoria poderia ser a real explicação para as razões de como as desigualdades socioeconômicas atuariam no processo saúde-doença e, embora haja uma bem estabelecida correlação entre cárie dental e fatores socioeconômicos, a influência dos processos sociais nos níveis de saúde pode variar de acordo com grupos e sociedades, e em determinados períodos de tempo (NEWTON; BOWER, 2005).

Assim, compreender a dinâmica de como a sociedade influencia o processo de saúde-doença e os parâmetros envolvidos nesse processo torna-se essencial para a implementação de políticas de promoção de saúde voltadas para a redução das ineqüidades na comunidade (DALY et al., 2002; MOYSÉS; RODRIGUES, 2004; WATT; SHEIHAM, 1999).

Porém, de acordo com Boing et al. (2005), o estudo das condições socioeconômicas é um tema bastante extenso que implica a utilização de diferentes formas de estratificação social visando à exploração desses parâmetros em sua relação com os níveis de saúde da comunidade em questão.

Os determinantes sociais que têm sido investigados na literatura podem ser determinados com dados disponíveis nas diversas organizações governamentais de cada localidade, e esse é um aspecto que deve ser considerado na escolha de qual indicador ou índice é mais bem aplicado na estratificação social da população. Ou seja, os parâmetros e fatores de risco sociais variam de acordo com a realidade e disponibilidade de dados de cada população (BOING; KOVALESKI; ANTUNES, 2006; NEWTON; BOWER, 2005). 
Para a população brasileira, fatores como renda, nível educacional dos pais, número de membros na família, moradia, taxa de analfabetismo, defasagem escolar, coesão social, índice de desenvolvimento infantil (IDI) e índice de desenvolvimento Humano (IDH), têm sido utilizados freqüentemente em estudos relacionando saúde bucal e determinantes sociais da população (ANTUNES et al., 2004b, 2006; BALDANI; NARVAI; ANTUNES, 2002; BOING et al. ,2005; FERNANDES; PERES, 2005; PATTUSSI et al., 2001; PERES et al., 2003). Um panorama geral da metodologia desses estudos e seus principais resultados pode ser visualizado no Apêndice A.

Considerando a importância do tema no que se refere à implementação de políticas públicas de promoção de saúde focadas nos determinantes socioeconômicos, será realizada, a seguir, uma síntese dos principais fatores utilizados na estratificação social em estudos epidemiológicos nacionais.

2.2.1 Avaliação dos determinantes socioeconômicos em estudos epidemiológicos

Ao iniciarmos uma breve discussão a respeito do tema, torna-se necessário entender que a aferição dos níveis socioeconômicos através de índices ou indicadores numéricos, apesar de ser uma prática usual na literatura, pode ser considerada um recurso que permite apenas uma aproximação da realidade social, sem deflagrar, muitas vezes, o complexo mecanismo de relacionamento causal entre essas condições e os padrões de saúde da população (ANTUNES, 2005; BOING et al., 2005; NEWTON; BOWER, 2005). Entretanto, de acordo com Antunes (2005), 
tais medidas tornam-se úteis por impulsionarem grandes avanços no entendimento dos determinantes de saúde na população.

Um outro aspecto importante a ser considerado é que uma determinada medida socioeconômica pode ter diferentes significados quando analisada em diferentes populações ou em diferentes grupos sociais. Assim, estudos devem considerar a validade de se utilizar uma determinada medida como indicador socioeconômico e ainda, quando essa medida não puder ser analisada (por exemplo, pela falta de dados nos bancos municipais) ou, então, quando tal variável não for de interesse para uma determinada população, as implicações dessa não inclusão devem ser discutidas (BRAVEMAN et al., 2005).

Diferentes critérios têm sido utilizados em estudos nacionais na estratificação social da população (BOING et al., 2005), sendo que a escolha de um determinado índice ou indicador deve sempre estar embasada na real importância de tal condição social ao desfecho considerado em saúde (ANTUNES, 2005). Níveis de instrução, renda, ocupação e de desenvolvimento humano, têm sido freqüentemente utilizados na literatura nacional.

Os indicadores de ocupação têm sido utilizados na medida em que referenciam um amplo aspecto das condições de vida que interessam à saúde, principalmente por serem dados de fácil obtenção e análise (BOING; KAVALESKI; ANTUNES, 2006). Categorias ocupacionais baseadas em prestígio, habilidades, influência social e poder têm sido a base para a classificação socioeconômica de diversos estudos baseados na premissa de indicarem práticas cotidianas como situações de estresse no trabalho, tempo disponível para lazer e situações diversas que podem interferir na probabilidade de desenvolvimento de doença (BRAVEMAN et al., 2005). 
A classificação da ocupação varia desde critérios como taxas de desemprego, tipo e horas de trabalho, até a utilização de sistemas classificatórios mais abrangentes (BOING; KAVALESKI; ANTUNES, 2006). Entretanto, deve-se considerar que a categorização de ocupação nem sempre captura as noções de prestígio e remuneração quando comparados estudos em diferentes padrões sociais, além de serem um desafio na análise de pessoas fora do mercado de trabalho, com atividades irregulares ou cronicamente desempregadas (BOING; KAVALESKI; ANTUNES, 2006; BRAVEMAN et al., 2005).

Níveis de instrução também têm sido um dos parâmetros freqüentemente associados às condições de saúde bucal. De acordo com Boing, Kavaleski e Antunes (2006), os níveis de instrução podem afetar a saúde através do favorecimento ao acúmulo de conhecimentos que podem influenciar a tomada de hábitos saudáveis, participação em profissões de melhores condições sociais devido à qualificação e por compartilharem os mesmos fatores estruturais que afetam os níveis de saúde. Além disso, baixos níveis de escolaridade podem também capturar o efeito cumulativo de adversidades socioeconômicas ao longo da vida de um indivíduo (MULLER, 2002).

Usualmente esses indicadores são aferidos através de taxas de analfabetismo, total de anos estudados, porcentagem de crianças matriculadas em escolas ou defasagem escolar média, sendo essas informações freqüentemente disponíveis em bases de dados macropopulacionais (BOING et al., 2005). Apesar de tal facilidade, os indicadores de educação como, por exemplo, anos de escola, podem não capturar diferenças significantes em termos de qualidade no processo de aprendizado, principalmente quando analisados comparativamente em diferentes populações (BRAVEMAN et al., 2005). 
Um parâmetro bastante utilizado nos estudos epidemiológicos são os indicadores de renda. Tal parâmetro é tido como medida diretamente relacionada com as condições materiais de vida, como condições de moradia e trabalho, acesso a conhecimento e cuidados com saúde, padrões de dieta e exposição a uma série de fatores que influenciam padrões diferenciados de riscos (BOING; KAVALESKI; ANTUNES, 2006; MACKENBACH, 2002; WILKINSON, 1997a).

As medidas de renda podem ser aferidas tomando-se parâmetros absoluto, como valores de renda média, percentual de pobreza e medidas de riqueza de uma população, ou então em termos relativos no que se refere às desigualdades na distribuição de renda.

A respeito disso, tem sido tema de grandes discussões na literatura a real influência de valores absolutos ou relativos de renda como indicadores de saúde (BEZRUCHKA, 2002; COCKERHAM; HATTORI; YAMORI, 2000; GRAVELLE, 1998; MACKENBACH, 2002; PATTUSSI et al., 2001; WILKINSON, 1997b; WILKINSON; BEZRUCHKA, 2002).

A hipótese de renda absoluta, a qual roga que quanto maior o rendimento individual, menor o risco de desenvolvimento de doenças - apesar de sustentada por alguns autores (GRAVELLE, 1998; MACKENBACH, 2002) - tem sido extensamente criticada (BEZRUCHKA, 2002; MOYSÉS, 2000; MULLER, 2002; PATTUSSI et al., 2001; WILKINSON, 1997a, 1997b; WILKINSON; BEZRUCHKA, 2002) por não conseguir explicar os diferentes padrões de doença encontrados entre diferentes populações.

Esse fato tem dado espaço à hipótese de renda relativa, segundo a qual, a desigualdade na distribuição de renda entre os membros da sociedade é que influencia o processo saúde-doença (WILKINSON, 1997a, 1997b; WILKINSON; 
BEZRUCHKA, 2002), sugerindo que não são as sociedades mais ricas, mas sim as mais igualitárias que possuem melhores quadros de saúde, ou seja, a extensão das ineqüidades, ou relativa pobreza, determina saúde (PATTUSSI et al., 2001).

De acordo com Wilkinson (1997a) e Wilkinson e Bezruchka (2002), as sociedades com maiores níveis de ineqüidades não só sofrem de maior privação relativa, mas também tendem a apresentar menores taxas de confiança e envolvimento em ações comunitárias e maiores níveis de violência (PATTUSSI et al., 2001; WILKINSON; BEZRUCHKA, 2002), reforçando o fato de que a saúde está mais relacionada aos padrões relativos de renda e status em uma sociedade, do que aos valores absolutos de padrões de vida.

Estudos relacionando os padrões de distribuição de renda e sua associação com cárie dental têm reforçado tal constatação (PATTUSSI et al., 2001; PATTUSSI; HARDY; SHEIHAM, 2006).

Dentre as medidas de desigualdade em termos de distribuição de renda, o coeficiente de Gini tem sido freqüentemente empregado para essa aferição (WAGSTAFF; VAN DOORSLAER, 2000). O resultado desse coeficiente apresenta valores que variam de "0" (quando não há desigualdade, isto é, todos os indivíduos recebem a mesma renda) a "1" (desigualdade máxima, isto é, um único indivíduo recebe toda a renda da sociedade). Estudos que utilizaram esse coeficiente como variável de aferição de renda podem ser visualizados no Apêndice $A$.

Um conceito promissor na estratificação social da população é a utilização de padrões de Desenvolvimento Humano Sustentável (DHS) da população. Tal conceito parte do pressuposto de que, para aferir o avanço de uma população, não se deve considerar apenas a dimensão econômica, mas também outras 
características sociais, culturais e políticas que influenciam a qualidade da vida humana .

Considerando a importância dessas dimensões na aferição dos padrões de desenvolvimento de uma região, o Programa das Nações Unidas para o Desenvolvimento (PNUD) publica, desde 1990, valores dos Índices de Desenvolvimento Humano (IDH). Esse índice foi criado e desenvolvido pelo economista paquistanês Mahbub ul Haq e visa a refletir as três dimensões fundamentais para o desenvolvimento humano de uma região: educação (mensurada pela taxa de alfabetização de adultos e pela taxa de escolarização bruta combinada no ensino fundamental, médio e superior); renda (mensurada pela renda municipal per capita considerando as diferenças de custo de vida em cada região, sendo valores expressos em dólar PPC- Paridade do Poder de Compra); e longevidade (medida pela esperança de vida ao nascer) (BOING; KAVALESKI; ANTUNES, 2006).

O IDH possui valores que variam de zero (nenhum desenvolvimento humano) a um (desenvolvimento humano total). Países com IDH até 0,499 têm desenvolvimento humano considerado baixo; os países com índices entre 0,500 e 0,799 são considerados de médio desenvolvimento humano e países com IDH superior a 0,800 têm desenvolvimento humano considerado alto.

Outro índice que abrange o conceito de Desenvolvimento Humano Sustentável é o Índice de Desenvolvimento Infantil (IDI). Esse índice foi desenvolvido pelo escritório regional do Fundo das Nações Unidas para Infância UNICEF - no Brasil, a partir da necessidade de promover e desenvolver políticas públicas orientadas para os primeiros seis anos de vida da criança, incorporando em suas dimensões variáveis relacionadas à oferta de serviços de saúde, à oferta de 
serviços de educação e ao cuidado e proteção que a família deve proporcionar à criança nos primeiros anos (representados pelo nível de educação do pai e da mãe).

Do mesmo modo que o IDH, o IDI possui resultados que variam de zero a um com seus valores discriminados para todas as unidades federativas e municipais do país.

Alguns índices compostos têm sido preconizados para a discriminação socioeconômica em diferentes estudos epidemiológicos na medida em que refletem uma série de indicadores. Entretanto muitos desses índices não podem ser aplicados em todas as populações, principalmente pela dificuldade ou falta de determinadas informações de alguns de seus componentes. Além disso, a utilização de indicadores compostos não permite o estudo de como um determinado fator influencia os parâmetros de saúde (BRAVEMAN et al., 2005).

Uma série de outros indicadores têm sido utilizados por pesquisadores em seus estudos relacionando cárie dental e condições socioeconômicas, dentre eles, valores de aglomeração domiciliar (ANTUNES et al., 2002; PATTUSSI et al., 2001); dados demográficos a respeito da rede de água de abastecimento (ANTUNES et al., 2004; PERES et al., 2003); grupo étnico (ANTUNES et al., 2003) e conceitos referentes às dimensões de coesão social (PATTUSSI et al., 2001; PATTUSSI; HARDY; SHEIHAM, 2006), sendo esta uma área promissora nos estudos dos determinantes em saúde bucal.

Todos esses parâmetros têm sido usados em diferentes estudos epidemiológicos, principalmente de delineamentos ecológicos que utilizam dados agregados. Tais estudos apresentam substancial vantagem quando se deseja explicar os efeitos contextuais de uma comunidade sobre a prevalência de uma doença (MOYSÉS; MOYSÉS, 2006) e têm-se tornado uma alternativa freqüente em 
estudos de cárie dental (ANTUNES et al., 2002, 2003, 2004a, 2006; BOING et al., 2005; EGRI; GUNAY, 2004; MUIRHEAD; MARCENES, 2004; NADANOVSKY; SHEIHAM, 1995; PATTUSSI et al., 2001; PERES et al., 2003), sendo reconhecidos como instrumentos efetivos para o desenvolvimento de pesquisas em saúde (NEWTON; BOWER, 2005; SUSSER; SUSSER, 1996a).

Ainda, a apresentação dos resultados de levantamentos epidemiológicos, segundo dados agregados relativos à área de abrangência, configura uma estratégia proveitosa para avaliar diferentes associações entre macrofatores e cárie dental, principalmente quando dados relativos a cada indivíduo da pesquisa não estão disponíveis (BOING; KAVALESKI; ANTUNES, 2006; MOYSÉS; MOYSÉS, 2006; EGRI; GUNAY, 2004).

Isso porque uma área populacional acaba sintetizando uma série de variáveis e processos, com alto grau de complexidade, aproximando, desta maneira, o estudo ecológico da realidade social de tal comunidade (KRIEGER, 2001).

A afirmação do caráter social do processo saúde-doença reforça cada vez mais a convicção de que os prejuízos à saúde são influenciados de forma substancial por fatores de ordem macroestruturais da sociedade (MOYSÉS; MOYSÉS, 2006). Os estudos epidemiológicos têm explorado tal afirmação através de associações de um agravo (cárie dental) com naturezas distintas, dentre elas as condições socioeconômicas. Essas associações têm sido testadas através de diferentes modelos explicativos, porém ainda há a necessidade de maiores estudos considerando os métodos utilizados na estratificação social da população e a interação de tais parâmetros nos níveis de cárie dental, principalmente em populações com diferentes estruturações culturais. Os resultados de tais estudos permitiriam a implementação de estratégias de atuação no processo saúde-doença 
voltadas aos determinantes básicos de saúde, possibilitando, assim, perspectivas reais de controle e promoção de saúde. 


\section{PROPOSIÇÃO}

O objetivo deste estudo foi avaliar a associação entre experiência de cárie dental e diferentes fatores socioeconômicos em crianças de 12 anos de idade nas capitais brasileiras, e verificar a influencia desses fatores na redução do índice de cárie nessas populações, nos anos de 1996 a 2003. 


\section{MATERIAL E MÉTODOS}

\subsection{Delineamento do estudo}

O presente estudo trata-se de uma pesquisa de delineamento ecológico com a utilização de dados agregados para verificar: (I) a associação entre experiência de cárie dental e indicadores socioeconômicos; e (II) os possíveis fatores associados à redução nos índices de cárie; tendo como unidades de análises todas as capitais nacionais.

Para a concretização do primeiro objetivo, utilizaram-se dados provenientes do último censo demográfico, realizado no ano de 2000 , que é a fonte mais recente de dados da população e de informações obtidas no Conselho Federal de Odontologia (CFO, 2006). Os resultados do projeto SBBrasil 2003 (BRASIL, 2004) foram utilizados para o registro dos índices CPO-D e porcentagem de crianças livres de cárie (CPO-D=0) em cada capital.

Para a segunda finalidade, além das informações descritas anteriormente, utilizaram-se os dados dos índices CPO-D do Levantamento Epidemiológico de Saúde Bucal realizado em 1996 pelo Ministério da Saúde. 


\subsection{Avaliação da experiência de cárie dental (índice CPO-D)}

Os dados a respeito da experiência de cárie dental foram obtidos através dos resultados provenientes do último Levantamento Epidemiológico Nacional de Cárie Dental inseridos no "Projeto SBBrasil 2003 - condições de saúde bucal da população brasileira 2002-2003" (BRASIL, 2004). Os resultados oficiais do SBBrasil 2003, bem como os procedimentos metodológicos utilizados na pesquisa, foram divulgados na forma de um relatório descritivo na página do Ministério da Saúde (http://dtr2001.saude.gov.br/editora/produtos/livros/zip/04 0347 M.zip).

metodologia utilizada para o levantamento seguiu as diretrizes internacionais empregadas pela Organização Mundial da Saúde (OMS) (WHO, 1997), avaliando uma amostra representativa de crianças de 12 anos em 250 municípios dos mais variados portes em cada uma das macrorregiões nacionais (OLIVEIRA, 2006).

\subsubsection{Características do Projeto SBBrasil 2003}

Durante os meses de maio de 2002 a outubro de 2003, a Coordenação Nacional de Saúde Bucal realizou um amplo levantamento epidemiológico, em nível nacional, a respeito das principais características da saúde bucal em diferentes grupos etários da população brasileira.

Esse estudo, intitulado "SB Brasil 2003 - Condições de Saúde Bucal na População Brasileira 2002-2003”, teve início em 1999, com a criação, em âmbito do 
Ministério da Saúde, de um subcomitê composto por 5 membros, representantes das macrorregiões administrativas brasileiras, o qual seria responsável pela elaboração e condução de um projeto de levantamento epidemiológico de saúde bucal no ano 2000. Em 2001 foi realizado um estudo piloto em duas cidades de diferentes portes populacionais - Canela-RS e Diadema-SP (BRASIL, 2004).

Durante o período do projeto, aproximadamente 2000 profissionais entre cirurgiões-dentistas, auxiliares e agentes de saúde estiveram envolvidos na realização do estudo, compreendendo um total de 108.921 exames clínicos realizados de acordo com os critérios estabelecidos pela OMS (WHO, 1997). O relatório completo do levantamento provê informações detalhadas a respeito dos procedimentos utilizados no processo de treinamento e calibração dos examinadores, bem como os coeficientes de concordância de Kappa intra e inter examinadores para cada condição bucal avaliada em cada grupo etário (BRASIL, 2004).

A amostra foi pré-estratificada de acordo com as macrorregiões brasileiras e por porte populacional do município, perfazendo um total de 250 municípios pesquisados. O Apêndice B apresenta as principais características desse levantamento.

Para a avaliação da experiência de cárie dental em crianças de 12 anos (índice CPO-D), foram utilizadas escolas como pontos de coleta, resultando em uma amostra representativa de 34.550 crianças examinadas.

Para o presente estudo, a experiência de cárie foi considerada tomando a idade de 12 anos como parâmetro por se tratar de uma idade índice (WHO, 1997). De acordo com a OMS (1997), nessa faixa etária pode-se avaliar a dentição permanente completa. Além disso, no Brasil, grande parte da população aos 12 
anos está matriculada em escolas (IBGE, 2001), tornando o estudo operacionalmente mais fácil.

Além dos valores do índice CPO-D em crianças de 12 anos, também se utilizaram os valores referentes à porcentagem de crianças livres de cárie nessa faixa etária (CPO-D=0).

\subsection{Avaliação dos indicadores socioeconômicos}

As informações a respeito das características socioeconômicas de cada capital foram obtidas a partir dados censitários (IBGE, 2001) e publicações oficiais das bases de dados do Ministério da Saúde, Fundação Instituto Brasileiro de Geografia e Estatística (IBGE), Conselho Federal de Odontologia (CFO), United Nations Children's Fund (UNICEF), Programa das Nações Unidas para o Desenvolvimento (PNUD) e Instituto de Pesquisa Econômica Aplicada (IPEA).

As seguintes variáveis foram utilizadas:

- Renda domiciliar per capita (R\$) (RDP): Obtida através da razão entre o somatório da renda familiar per capita de todos os moradores de um mesmo domicílio e o total destes indivíduos (IPEA, 2006);

- Pobreza - pessoas pobres (\%) (POB): Percentual de pessoas com idade de zero a 14 anos que têm renda domiciliar per capita inferior à linha de pobreza de $\mathrm{R} \$ 75,50$ (meio salário mínimo de agosto de 2000) (IBGE, 2006); 
- Desigualdade na distribuição de renda (GINI): a desigualdade na distribuição de renda nas diferentes capitais foi ilustrada através do coeficiente de Gini, que mede o grau de desigualdade existente na distribuição de indivíduos segundo a renda domiciliar per capita (IPEA, 2006);

- Taxa de analfabetismo infantil (\%) (ANALF): refere-se ao percentual de pessoas com idade de 7 a 14 anos que não sabem ler nem escrever (IBGE, 2006);

- Defasagem escolar média (DFESC): proporção de crianças de 7 a 14 anos com mais de um ano de atraso na escola (IBGE, 2006).

- Exclusão escolar (EXCESC): refere-se à proporção de crianças de 7 a 14 anos que não estejam matriculadas em escolas (IBGE, 2006);

- Aglomeração domiciliar (\%) (DENSD): percentual de pessoas que vivem em domicílios com densidade superior a 2. A densidade do domicílio é dada pela razão entre o total de moradores do domicílio e o número total de cômodos do mesmo, excluídos o(s) banheiro(s) e mais um cômodo, destinado à cozinha (IPEA, 2006);

- Porcentagem de distritos municipais com água fluoretada (FLU) (IBGE, 2006);

- Taxa de cirurgiões-dentistas por habitantes (CD): razão entre o número de cirurgiões-dentistas inscritos no Conselho Regional de Odontologia (CRO) para cada município e o número de habitantes do município (ajustado por 10.000 habitantes) (CFO, 2006).

Além dos indicadores sócio-demográficos, foram incorporados dados relativos a dois índices compostos de desenvolvimento social: o índice de desenvolvimento humano (IDH) (IBGE), e o índice de desenvolvimento infantil (IDI) (PNUD, 2006). 


\subsection{Percentual de redução no índice CPO-D}

Os valores observados nos índices CPO-D de cada capital em 2003 (BRASIL, 2004) foram comparados com os dados a respeito do Levantamento Nacional em Saúde Bucal realizado pelo Ministério da Saúde em 1996, para o cálculo do percentual de redução de cárie entre esses dois exames.

A metodologia do levantamento de 1996 tomou por base algumas orientações da OMS, a partir da $3^{\mathrm{a}}$ edição do seu Manual para Levantamentos Epidemiológicos em Saúde Bucal, de 1987. Foram feitos exames em escolares de 6 a 12 anos de escolas públicas e privadas, incluindo somente as 27 capitais brasileiras. Em cada capital foram examinadas 1.120 crianças, perfazendo um total de 30.240 em todo o País (RONCALLI, 1998). Embora não tenha sido publicado nenhum relatório específico do levantamento, os dados descritivos podem ser encontrados na página do Ministério da Saúde (www.saudebucalnobrasil.sjb.net) e também em um "Relatório paralelo" disponível na Internet (www.angelonline.cjb.net) (RONCALLI, 1998).

\subsection{Análise dos dados}

Todos os dados referentes a cada capital foram inseridos em uma planilha do programa Microsoft Excel pelo próprio pesquisador. Com o intuito de prevenir erros de digitação, os dados foram computados duas vezes, sendo posteriormente 
transferidos para o programa SPSS versão 13.0, no qual foram realizadas as análises estatísticas.

Primeiramente realizou-se uma análise exploratória dos dados referentes às variáveis estudadas.

As variáveis de desfecho consideradas no presente estudo foram: CPO-D, percentual de crianças livres de cárie e percentual de redução de cárie. Para avaliar a existência de associação entre as variáveis de desfecho consideradas no estudo e as demais variáveis socioeconômicas, foram calculados os coeficientes de correlação de Pearson. Foi também realizada análise de regressão linear simples para descrever a relação linear existente entre cada variável de desfecho e as demais variáveis consideradas no estudo.

Após essa etapa, foram realizadas análises de regressão linear múltipla para verificar o efeito combinado das variáveis que apresentaram associação estatística aos desfechos (identificadas na análise de regressão simples). O método de seleção das variáveis utilizado na construção dos modelos foi o stepwise, considerando-se o nível de significância para a inclusão das variáveis de $5 \%$ e o de exclusão de $10 \%$. Para cada modelo selecionado, procedeu-se a análise de resíduos para verificar a existência de outliers.

Os modelos da regressão foram definidos pela equação:

$$
E(Y)=\beta_{0}+\beta_{1} X_{1}+\beta_{2} X_{2}+\ldots \ldots \ldots \beta_{i} X_{1}+\varepsilon
$$

em que:

$E(Y)$ : variável dependente; 
$\beta_{0}$ : coeficiente linear (interceptor);

$\beta_{1}$ : parâmetro do modelo;

ع: resíduo

Também foram calculados os coeficientes de determinação ajustados $\left(R^{2}\right)$ para cada modelo final da análise de regressão. Esse coeficiente consiste em uma medida de associação entre a variável dependente e as variáveis explicativas e descreve a proporção da variabilidade do desfecho que pode ser atribuída à relação entre ele e as variáveis independentes. Esse coeficiente assume valores entre 0 e 1; logo, quanto mais próximo de 1 estiver o $\mathrm{R}^{2}$, maior a proporção da variação total em "y" que é explicada pelo modelo.

Antes da realização das análises de regressão foi aplicado o teste de Kolmogorov-Smirnov para determinar a normalidade das variáveis e os testes de Kendall-Stuart e de Goldfeld-Quandt para avaliar homoscedasticidade.

De forma exploratória, também se procurou ajustar modelos aditivos generalizados (GAM) para investigar a existência de uma possível relação não linear entre as variáveis de desfecho e cada uma das variáveis explicativas. Porém, nenhuma relação não linear foi identificada, então, prosseguiu-se a análise com o ajuste de modelos de regressão linear. 


\section{RESULTADOS}

Os valores descritivos de todas as variáveis socioeconômicas estudadas e a experiência de cárie nas capitais segundo sua distribuição em percentis, medidas de tendência central e de dispersão, estão expressos na tabela 5.1.

Tabela 5.1 - Medidas descritivas dos indicadores socioeconômicos e experiência de cárie dental nas capitais nacionais $(n=26)$. Brasil

\begin{tabular}{lcccccc}
\hline Variável & Média (d.p.) & Mínimo & Percentil 25 & Mediana & Percentil 75 & Máximo \\
\hline CPOD & $2,07(0,84)$ & 0,91 & 1,27 & 1,80 & 2,83 & 3,51 \\
LC & $38,64(13,18)$ & 19,50 & 25,68 & 37,8 & 48,16 & 64,80 \\
CD & $19,54(9,97)$ & 6,80 & 12,89 & 18,50 & 24,92 & 49,30 \\
ANALF & $8,84(3,97)$ & 2,70 & 5,10 & 9,45 & 11,98 & 18,30 \\
DFESC & $20,9(7,27)$ & 9,60 & 14,50 & 21,55 & 27,00 & 35,00 \\
DENSD & $23,94(10,46)$ & 10,21 & 16,48 & 20,70 & 30,59 & 45,87 \\
POB & $34,94(11,78)$ & 13,18 & 23,52 & 37,94 & 45,14 & 51,67 \\
GINI & $0,63(0,03)$ & 0,57 & 0,61 & 0,62 & 0,65 & 0,68 \\
RDP & $412,25(153,75)$ & 251,00 & 295,34 & 347,03 & 567,24 & 709,00 \\
IDH & $0,80(0,05)$ & 0,60 & 0,77 & 0,80 & 0,84 & 0,88 \\
IDI & $0,66(0,05)$ & 0,56 & 0,63 & 0,67 & 0,69 & 0,77 \\
EXESC & $24,73(9,76)$ & 10,80 & 15,88 & 22,25 & 35,45 & 42,18 \\
HOM & $0,44(0,19)$ & 0,14 & 0,28 & 0,41 & 0,54 & 0,92 \\
FLU & $63,42(45,62)$ & 0,00 & 0,00 & 100,00 & 100,00 & 100,00 \\
\hline
\end{tabular}

d.p: desvio padrão; CPOD: índice de dentes cariados, perdidos ou obturados; LC: crianças livres de cárie (\%); CD: cirurgiões dentistas residentes no município ; ANALF: analfabetismo infantil (\%); DEFESC: defasagem escolar (\%); DENSD: aglomeração domiciliar (\%); POB: pessoas pobres (\%); GINI: coeficiente de Gini; RDP: renda per capita média (R\$); IDH: índice de desenvolvimento humano; IDI: índice de desenvolvimento infantil; EXESC: exclusão escolar (\%); HOM: taxa de homicídios; FLU: distritos com água fluoretada (\%).

A tabela 5.1 demonstra que o CPO-D médio da amostra foi de 2,07 (d.p=0,84), com uma considerável discrepância entre os valores mínimo $(0,91$ Aracajú - SE) e máximo (3,51 - Manaus-AM). O mesmo pode ser observado com a 
média da proporção de crianças livres de cárie da amostra $(38,64 \%$ - d.p=13,18), cujos resultados variaram de 19,5 à $64,8 \%$ respectivamente para os municípios de Rio Branco-AC e São Paulo-SP.

As circunstâncias socioeconômicas também apresentaram consideráveis variações entre as capitais estudadas. Por exemplo, a taxa de analfabetismo infantil (porcentagem de crianças de 0 a 14 anos que não sabem ler nem escrever) variou de 2,7 a 18,3\%, respectivamente para os municípios de Curitiba-PR e Maceió-AL. Contrastes em termos de distribuição dos valores também podem ser visualizados no que se refere às variáveis de renda, moradia e a taxa de cirurgiões-dentistas que trabalham nos municípios (Tabela 5.1).

A tabela 5.2 apresenta a matriz de correlação (coeficiente de correlação de Pearson) entre todas as variáveis socioeconômicas e as variáveis de desfecho consideradas no estudo. 
Tabela 5.2 - Matriz de correlação ${ }^{a}$ entre indicadores socioeconômicos municipais e variáveis de desfecho consideradas na capitais nacionais ( $\left.n=26\right)$. Brasil

\begin{tabular}{|c|c|c|c|c|c|c|c|c|c|c|c|c|c|c|c|}
\hline & CPOD & LC & CD & ANALF & DFESC & DENSD & POB & GINI & RDPE & $\mathrm{IDH}$ & IDI & EXESC & $\mathrm{HOM}$ & FLU & RED \\
\hline CPOD & 1 & & & & & & & & & & & & & & \\
\hline LC & $-0,94 * *$ & 1 & & & & & & & & & & & & & \\
\hline$C D$ & $-0,47^{*}$ & 0,58 ** & 1 & & & & & & & & & & & & \\
\hline ANALF & 0,35 & $-0,38$ & $-0,63 * *$ & 1 & & & & & & & & & & & \\
\hline DFESC & 0,37 & $-0,38$ & $-0,61 * *$ & $0,88 * *$ & 1 & & & & & & & & & & \\
\hline DENSD & 0,31 & $-0,38$ & $-0,78^{* *}$ & $0,50 * *$ & 0,42 * & 1 & & & & & & & & & \\
\hline POB & 0,42 * & $-0,42 *$ & $-0,70 * *$ & $0,91 * *$ & $0,85^{* *}$ & $0,53 * *$ & 1 & & & & & & & & \\
\hline GINI & 0,26 & $-0,28$ & $-0,41$ * & $0,71^{* *}$ & $0,71^{* *}$ & 0,20 & 0,76 ** & 1 & & & & & & & \\
\hline RDP & $-0,59 * *$ & $0,59^{* *}$ & $0,85^{* *}$ & $-0,79 * *$ & $-0,78 * *$ & $-0,66$ ** & $-0,90 * *$ & $-0,60 * *$ & 1 & & & & & & \\
\hline IDH & $-0,51 * *$ & $0,54 * *$ & $0,69 * *$ & $-0,56 * *$ & $-0,42$ * & $-0,60 * *$ & $-0,60 * *$ & $-0,15$ & $0,74 * *$ & 1 & & & & & \\
\hline IDI & $-0,47^{*}$ & $0,52 * *$ & $0,74^{* *}$ & $-0,74^{* *}$ & $-0,69 * *$ & $-0,50$ * & $-0,65^{* *}$ & $-0,56 * *$ & 0,72 ** & 0,46 * & 1 & & & & \\
\hline EXESC & 0,17 & $-0,20$ & $-0,33$ & $-0,06$ & $-0,28$ & 0,40 & $-0,17$ & $-0,23$ & $-0,03$ & $-0,01$ & $-0,42$ * & 1 & & & \\
\hline HOM & $-0,22$ & 0,23 & 0,27 & 0,02 & $-0,04$ & $-0,16$ & $-0,07$ & 0,11 & 0,21 & 0,04 & 0,12 & $-0,09$ & 1 & & \\
\hline FLU & $-0,47$ * & 0,43 * & 0,31 & $-0,42$ * & $-0,47$ * & $-0,28$ & $-0,37$ & $-0,40$ * & 0,43 * & 0,20 & 0,36 & $-0,21$ & $-0,18$ & 1 & \\
\hline RED & $-0,60 * *$ & $0,43^{* *}$ & 0,12 & $-0,21$ & $-0,28$ & $-0,05$ & $-0,33$ & $-0,40$ * & 0,28 & 0,06 & 0,23 & $-0,03$ & 0,09 & 0,27 & 1 \\
\hline
\end{tabular}

${ }^{a}$ Coeficiente de correlação de Pearson: $\left({ }^{*} p<0,05 ;{ }^{* *} p<0,01\right)$

CPOD: índice de dentes cariados, perdidos ou obturados; LC: crianças livres de cárie; CD: cirurgiões-dentistas residentes no município; ANALF: analfabetismo infantil DEFESC: defasagem escolar; DENSD: aglomeração domiciliar; POB: pessoas pobres; GINI: coeficiente de Gini; RDP: renda per capita média; IDH: índice de

desenvolvimento humano; IDI: índice de desenvolvimento infantil; EXESC: exclusão escolar; HOM: taxa de homicídios e/ou tentativas de homicídios; FLU: distritos com água fluoretada; RED: percentual de redução no CPO-D. 
De acordo com a tabela 5.2, pode-se observar que há correlação entre os indicadores socioeconômicos municipais e a experiência de cárie dental (CPO-D). Em geral, os municípios com melhores perfis socioeconômicos apresentaram menores valores de CPO-D. Também se pode observar correlação negativa entre os valores de CPO-D e a taxa de cirurgiões-dentistas que trabalham nos municípios ( $r=-$ $0,47 ; p<0,05)$. Houve uma forte correlação entre os índices CPO-D e a proporção de crianças livres de cárie $(r=-0,94 ; p<0,01)$, demonstrando que as capitais com menores valores de CPO-D apresentaram também maior desigualdade na distribuição de doença cárie.

Do mesmo modo que a variável CPO-D, pode-se observar que a porcentagem de crianças livres de cárie apresentou correlação com os indicadores socioeconômicos, sendo que melhores condições socioeconômicas apresentadas por capitais com maiores porcentagens de crianças livres de doença. Ao contrário do observado em relação ao CPO-D, a taxa de cirurgiões-dentistas em cada município apresentou correlação positiva com a porcentagem de crianças livres de cárie $(r=0,58 ; p<0,01)($ Tabela 5.2).

Ainda de acordo com a tabela 5.2, pode-se constatar que o percentual de redução nos índices CPO-D entre 1996 e 2003 está associado com o coeficiente de Gini $(r=-0,40 ; p<0,05)$, CPO-D ( $r=-0,60 ; p<0,01)$, e porcentagem de crianças livres de cárie $(r=0,43 ; p<0,01)$. Isso indica que maiores percentuais de redução foram observados em capitais com menores valores de CPO-D e maiores porcentagens de crianças livres de cárie em 2003 (BRASIL, 2004), e em capitais com menores índices de desigualdade na distribuição de renda, ou seja, com menores níveis de ineqüidades. 
Os resultados das análises de regressão linear simples entre cada variável preditora e os desfechos considerados no estudo, bem como os respectivos coeficientes de determinação e significância estatística, estão expressos nas tabelas 5.3 à 5.5.

\begin{tabular}{|c|c|c|c|}
\hline Variável & Coeficiente de regressão (e.p) & $\mathrm{R}^{2}$ & $P$ \\
\hline CD & $-0,04(0,15)$ & 0,22 & 0,05 \\
\hline ANALF & $0,07(0,04)$ & 0,12 & 0,08 \\
\hline DFESC & $0,04(0,02)$ & 0,13 & 0,06 \\
\hline DENSD & $0,03(0,02)$ & 0,10 & 0,12 \\
\hline POB & $0,03(0,01)$ & 0,18 & 0,03 \\
\hline GINI & $7,9(6,02)$ & 0,07 & 0,20 \\
\hline RDP & $-0,003(0,001)$ & 0,34 & 0,002 \\
\hline IDH & $-7,8(2,7)$ & 0,26 & 0,007 \\
\hline IDI & $-8,4(3,3)$ & 0,22 & 0,02 \\
\hline EXESC & $0,02(0,02)$ & 0,03 & 0,4 \\
\hline HOM & $-0,97(0,90)$ & 0,05 & 0,3 \\
\hline FLU & $-0,00(0,00)$ & 0,22 & 0,02 \\
\hline
\end{tabular}

$R^{2}$ : Coeficiente de determinação; e.p: erro padrão

De acordo com a tabela 5.3, pode-se observar que houve associação estatisticamente significante entre os valores de CPO-D e a taxa de cirurgiões dentistas que trabalham no município $(p=0,05)$, o percentual de pessoas pobres $(p=0,03)$, a renda per capita média $(p<0,01)$, o IDH $(p<0,01)$, o IDI $(p=0,02)$, e a porcentagem de distritos municipais com fluoretação na água de abastecimento $(p=0,02)$. 
A tabela 5.4 apresenta os resultados da análise de regressão linear simples entre os indicadores socioeconômicos e a porcentagem de crianças livres de cárie.

\begin{tabular}{|c|c|c|c|}
\hline Variável & Coeficiente de regressão (e.p) & $\mathrm{R}^{2}$ & $p$ \\
\hline CD & $0,76(0,15)$ & 0,33 & 0,002 \\
\hline ANALF & $-1,26(0,63)$ & 0,15 & 0,06 \\
\hline DFESC & $-0,68(0,34)$ & 0,14 & 0,06 \\
\hline DENSD & $-0,48(0,24)$ & 0,15 & 0,052 \\
\hline POB & $-0,47(0,21)$ & 0,18 & 0,03 \\
\hline GINI & $-133,3(95,85)$ & 0,08 & 0,17 \\
\hline RDP & $0,05(0,01)$ & 0,32 & 0,001 \\
\hline $\mathrm{IDH}$ & $132,43(42,19)$ & 0,29 & 0,004 \\
\hline IDI & $149,10(49,63)$ & 0,27 & 0,006 \\
\hline EXESC & $-0,27(0,27)$ & 0,04 & 0,33 \\
\hline $\mathrm{HOM}$ & $16,07(13,95)$ & 0,05 & 0,26 \\
\hline FLU & $0,13(0,05)$ & 0,19 & 0,03 \\
\hline
\end{tabular}

$R^{2}$ : Coeficiente de determinação; e.p: erro padrão

De acordo com a tabela 5.4, pode-se observar que houve associação estatisticamente significante entre a porcentagem de crianças livres de cárie e a taxa de cirurgiões dentistas que trabalham no município $(p<0,01)$, o percentual de pessoas pobres $(p=0,03)$, a renda per capita média $(p<0,01)$, o IDH e IDI (ambos com $p<0,01)$, e a porcentagem de distritos municipais com fluoretação na água de abastecimento $(p=0,03)$. 
A tabela 5.5 apresenta os resultados da análise de regressão linear simples entre todas as variáveis e o percentual de redução nos valores de CPO-D entre 1996 e 2003.

Tabela 5.5 - Resultados da análise de regressão linear simples entre todas as variáveis e o percentual de redução nos valores de CPO-D nas capitais nacionais $(n=26)$. Brasil

\begin{tabular}{lccc}
\hline Variável & Coeficiente de regressão (e.p) & $R^{2}$ & $p$ \\
\hline CD & $0,29(0,48)$ & 0,02 & 0,54 \\
ANALF & $-1,28(1,18)$ & 0,05 & 0,29 \\
DFESC & $-0,91(0,63)$ & 0,08 & 0,16 \\
DENSD & $-0,12(0,46)$ & 0,003 & 0,8 \\
POB & $-0,67(0,38)$ & 0,11 & 0,1 \\
GINI & $-340,34(162,06)$ & 0,16 & 0,05 \\
RDP & $0,04(0,03)$ & 0,08 & 0,16 \\
IDH & $27,05(89,31)$ & 0,004 & 0,80 \\
IDI & $119,21(101,13)$ & 0,06 & 0,25 \\
EXESC & $-0,07(0,49)$ & 0,001 & 0,9 \\
HOM & $11,80(25,49)$ & 0,009 & 0,65 \\
CPOD & $-16,97(4,60)$ & 0,36 & 0,001 \\
LC & $0,77(0,33)$ & 0,19 & 0,03 \\
FLU & $0,14(0,10)$ & 0,08 & 0,18 \\
\hline
\end{tabular}

$R^{2}$ : Coeficiente de determinação; e.p: erro padrão

De acordo com a tabela 5.5, pode-se observar que houve associação estatisticamente significante entre o percentual de redução e a porcentagem de crianças livres de cárie $(p=0,03)$, o índice de CPO-D $(p<0,01)$, e o coeficiente de Gini $(p=0,05)$. 
Os Apêndices C e D apresentam os diagramas de dispersão e as curvas suavizadas das variáveis estatisticamente significantes $(p<0,05)$ em função da duas principais variáveis de desfechos consideradas neste estudo (porcentagem de crianças livres de cárie e índice CPO-D). De acordo com os diagramas apresentados pode-se verificar que, tanto para o índice CPO-D, como para a porcentagem de crianças livres de cárie, o município de Boa Vista apresenta-se como um ponto discrepante, com valor extremo baixo no que se refere à variável IDH $(0,604)$.

Dessa maneira, as análises de regressão linear múltipla foram realizadas incluindo ou não esse município para a composição do modelo final.

A tabela 5.6 apresenta os resultados da análise de regressão linear múltipla e as variáveis incluídas nos modelos considerando CPO-D como desfecho.

Tabela 5.6 -Resultados da análise de regressão linear múltipla (stepwise) entre as variáveis significantes e índice CPO-D nas capitais nacionais, Brasil

\begin{tabular}{ccccc}
\hline Variável & $\begin{array}{c}\text { Coeficiente de regressão } \\
\text { ajustado (IC 95\%) }\end{array}$ & $p$ & $R^{2}$ & e.p \\
\hline$\frac{\text { Modelo 1* }}{\text { RDP }}$ & $\begin{array}{c}-0,003 \\
(-0,005 ;-0,001)\end{array}$ & 0,002 & & 0,69 \\
Modelo 2 & & & \\
IDH & $-13,8$ & 0,37 & 0,68 \\
& $(-21,6 ;-6,01)$ & 0,001 & & \\
\hline
\end{tabular}

$\mathrm{R}^{2}$ : Coeficiente de determinação ajustado; e.p: erro padrão; IC 95\%: intervalo de confiança

* Modelo 1: considerando 26 capitais

** Modelo 2: considerando 25 capitais (excluindo Boa Vista)

De acordo com a tabela 5.6, pode-se verificar que, ao incluir todas as capitais na análise (Modelo 1), apenas a variável renda per capita apresentou associação significante com o índice CPO-D após o ajuste do modelo. O modelo apresentando essa variável foi responsável por $32 \%$ na variação dos valores de CPO-D $(p<0,05)$. 
Para verificar o ajuste do Modelo 1, realizou-se a análise de resíduos, na qual observou-se que a presença do município de Boa Vista atuava como um ponto influente (Apêndice C). Para avaliar o impacto desse município na estimativa do modelo, os coeficientes foram re-estimados excluindo essa capital (Tabela 5.6 Modelo 2).

Assim, quando a análise era realizada excluindo o município de Boa Vista, apenas a variável IDH apresentou associação com o índice CPO-D, sendo que, após o ajuste do modelo, o coeficiente de determinação passou de 0,32 para 0,37. De acordo com esse modelo, a variável IDH explica $37 \%$ da variação dos valores do CPO-D (Tabela 5.6 - Modelo 2).

A tabela 5.7 apresenta os resultados da análise de regressão linear múltipla e as variáveis incluídas nos modelos considerando a porcentagem de crianças livres de cárie como desfecho.

Tabela 5.7-Resultados da análise de regressão linear múltipla (stepwise) entre as variáveis significantes e a porcentagem de crianças livres de cárie nas capitais nacionais, Brasil

\begin{tabular}{|c|c|c|c|c|}
\hline Variável & $\begin{array}{c}\text { Coeficiente de regressão } \\
\text { ajustado (IC 95\%) }\end{array}$ & $p$ & $\mathrm{R}^{2}$ & e.p \\
\hline Modelo $1^{*}$ & & & 0,35 & 10,8 \\
\hline \multirow[t]{2}{*}{ RDP } & 0,05 & 0,001 & & \\
\hline & $(0,02 ; 0,08)$ & & & \\
\hline Modelo $2^{* *}$ & & & 0,32 & 10,7 \\
\hline \multirow[b]{2}{*}{ IDH } & 211,24 & & & \\
\hline & $(87,8 ; 334,7)$ & 0,002 & & \\
\hline
\end{tabular}


Ao analisarmos a tabela 5.7, verifica-se uma situação semelhante ao ocorrido com a variável CPO-D. Em um primeiro momento, quando todas as capitais eram incluídas na análise (Modelo 1), apenas a variável renda per capita apresentou associação significante com a porcentagem de crianças livres de cárie após o ajuste do modelo. O modelo apresentando essa variável foi responsável por $35 \%$ na variação dos valores de CPO-D $(p<0,05)$.

Porém, ao realizarmos a análise excluindo o município de Boa Vista, apenas a variável IDH apresentou associação significante com o desfecho, sendo que o coeficiente de determinação passou de 0,35 para 0,32 (Tabela 5.7).

A tabela 5.8 apresenta os resultados da análise de regressão linear múltipla e as variáveis incluídas nos modelos considerando o percentual de redução no índice CPO-D entre os levantamentos de 1996 e 2003.

Tabela 5.8 -Resultados da análise de regressão linear múltipla (stepwise) entre as variáveis significantes e percentual de redução nos CPO-D entre 1996 e 2003

\begin{tabular}{|c|c|c|c|c|}
\hline Variável & $\begin{array}{c}\text { Coeficiente de regressão } \\
\text { ajustado (IC 95\%) }\end{array}$ & $p$ & $\mathrm{R}^{2}$ & e.p \\
\hline Modelo 1* & & & 0,46 & 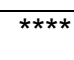 \\
\hline \multirow[t]{2}{*}{ CPO-D } & $-44,32$ & 0,001 & & \\
\hline & $(-68,45 ;-20,13)$ & & & \\
\hline \multirow[t]{2}{*}{ LC } & $-1,86$ & 0,02 & & \\
\hline & $(-3,40 ;-0,32)$ & & & \\
\hline Modelo $2^{* *}$ & & & 0,47 & $* * * *$ \\
\hline \multirow[t]{2}{*}{ CPO-D } & $-37,7$ & 0,002 & & \\
\hline & $(-59,8 ;-15,6)$ & & & \\
\hline \multirow[t]{2}{*}{ LC } & $-1,7$ & 0,02 & & \\
\hline & $(-3,08 ;-0,32)$ & & & \\
\hline \multirow[t]{2}{*}{ GINI } & $-250,6$ & 0,04 & & \\
\hline & $(-380,7 ;-115,7)$ & & & \\
\hline
\end{tabular}

$\mathrm{R}^{2}$ : Coeficiente de determinação ajustado; e.p: erro padrão; IC 95\%: intervalo de confiança

* Modelo 1: considerando 26 capitais

** Modelo 2: considerando 25 capitais (excluindo Manaus) 
De acordo com a tabela 5.8, o modelo final incluindo todas as capitais (Modelo $1-n=26$ ) apontou como preditores para a variação nos índices CPO-D entre os exames de 1996 e 2003, a porcentagem de crianças livres de cárie $(p=0,02)$ e os valores de CPO-D $(p<0,01)$ no último levantamento. O modelo apresentando essas variáveis explica $46 \%$ da variação nos valores de redução do CPO-D.

Entretanto, após a análise de resíduo, verificou-se a presença de um outlier (Manaus - Apêndice E). Ao realizarmos a análise excluindo esse município pôde-se verificar que o modelo final (Modelo 2) incluiu também a variável GINI. Com a inclusão dessa variável, houve um aumento marginal no coeficiente de determinação de 0,46 para 0,47 (Tabela 5.8 ). 


\section{DISCUSSÃO}

O conhecimento dos reais determinantes do processo saúde-doença é uma das questões primordiais para se promover saúde na população. Embora o conceito equivocado, que reduz saúde bucal a uma mera questão de manter "dentes limpos", ainda tenha seus adeptos na odontologia contemporânea, reduções nos níveis dessa doença só serão alcançadas a partir de ações amplas que visem à redução das ineqüidades em saúde (BÖNECKER; MARCENES; SHEIHAM, 2002; DALY et al., 2002; MOYSÉS, RODRIGUES, 2004; WATT; SHEIHAM, 1999).

A literatura tem demonstrado a bem-estabelecida relação entre fatores de ordem social, econômica e ambiental e uma série de condições bucais de uma população, dentre elas, cárie dental (LOCKER, 2000; WATT; SHEIHAM, 1999). Tal constatação ressalta o fato de essa doença ser um reflexo das desigualdades socioeconômicas vivenciadas em diferentes populações (DALY et al., 2002; PATTUSSI; HARDY; SHEIHAM, 2006; WATT; SHEIHAM, 1999).

Disparidades de ordem históricas, sociais e econômicas são características marcantes do cenário brasileiro, o que traz como conseqüência a formação de ambientes com perfis de saúde distintos, proporcionando quadros de maior prevalência de doenças em populações com piores indicadores socioeconômicos (BALDANI; NARVAI; ANTUNES, 2002). Essa situação também pôde ser observada no presente estudo.

Pôde-se verificar que houve correlações estatisticamente significantes entre diversos indicadores socioeconômicos avaliados e a experiência de cárie dental na população (Tabela 5.2). Em geral, capitais com melhores perfis socioeconômicos 
apresentaram menores valores de CPO-D e maior porcentagem de crianças livres de cárie em 2002-2003.

Esses resultados reforçam a prerrogativa de que a influência contextual das desigualdades socioeconômicas pode agir como fator explicativo da variação nos índices de cárie dental encontrada em municípios (DALY et al., 2002; NEWTON; BOWER, 2005; SUSSER; SUSSER, 1996b).

Embora uma comparação direta desses resultados com outros achados seja difícil de se realizar, principalmente devido às diferentes dimensões que esses determinantes podem adquirir em populações distintas (BRAVEMAN et al., 2005), estudos realizados em âmbito nacional corroboram com os dados encontrados a partir das análises realizadas (ANTUNES et al., 2002; 2006; BALDANI; NARVAl; ANTUNES, 2002; PERES et al., 2003).

Neste estudo, as associações entre os indicadores socioeconômicos e as variáveis de desfechos foram quantificadas através do coeficiente de correlação de Pearson (Tabela 5.2) e analisadas através de análise de regressão linear simples (Tabelas 5.3 a 5.5) e múltipla (Tabelas 5.6 a 5.8). A escolha da realização da análise de regressão visou a descrever a forma como se dá a relação existente entre uma variável dependente e uma determinada variável independente (análise de regressão linear simples) e o peso de cada variável independente quando avaliados conjuntamente (análise de regressão linear múltipla).

Os valores do coeficiente de correlação de Pearson entre as variáveis estudadas estão expressos na tabela 5.2. De acordo com essa tabela, pode-se verificar que houve associação significante entre o índice CPO-D e porcentagem de crianças livres de cárie com fatores socioeconômicos como IDH, IDI, percentual de pessoas vivendo abaixo da linha de pobreza (POB), renda per capita (RDP) e 
número de cirurgiões-dentistas inscritos no CRO do município por 10.000 habitantes (CD).

Os valores de renda per capita foram associados negativamente com os valores do índice CPO-D ( $r=-0,59 ; p<0,01$ - Tabela 5.2) e positivamente com a porcentagem de crianças livres de cárie $(r=0,59 ; p<0,01$ - Tabela 5.2), indicando que capitais com maiores valores de renda per capita apresentaram menores valores de CPO-D e uma maior porcentagem de crianças livres de cárie. Essa variável manteve-se significantemente associada a esses desfechos mesmo após ajustada pelas demais variáveis (Tabelas 5.6 e 5.7). Através da análise de regressão linear múltipla, o modelo final incluindo a variável renda foi responsável por $32 \%$ da variação dos valores do índice CPO-D (Tabela 5.6) e por 35\% da variação na porcentagem de crianças livres de cárie (Tabela 5.7).

A associação entre valores de renda e níveis de saúde é bem documentada na literatura (BRAVEMAN et al., 2005; MACKENBACH, 2002; WAGSTAFF; VAN DOORSLAER, 2000; WILKINSON, 1997a, 1997b). Estudos têm demonstrado alta correlação, por exemplo, entre renda e mortalidade, embora nem sempre essa associação seja causal (MACKENBACH, 2002). Renda pode estar associada a estilo de vida, preferência alimentar, personalidade, acesso ao conhecimento e uma série de outras variáveis que acabam influenciando indiretamente a saúde (BLAKELY et al., 2004; NARVAl et al., 2006).

Tal associação também tem sido demonstrada em outros estudos nacionais considerando cárie dental como agravo (ANTUNES et al., 2002; 2004a; 2006; NARVAl et al., 2006), concordando com os resultados apresentados neste estudo.

Entretanto, quando a saúde é diretamente relacionada com valores de renda, os resultados são ambíguos. Diversos autores têm discutido que os valores de 
aferição absoluta de renda não são parâmetros plausíveis de distinção social (WILKINSON, 1997a). Os problemas parecem refletir as dificuldades de se compararem os valores de renda entre diferentes populações e o valores de mensurações auto-referidas de renda devido à omissão de informações. A coleta dos dados de renda pode estar sendo omitida, por exemplo, porque existem dificuldades de se saber renda de pessoas que não estão na força de trabalho como autônomos e desempregados (BRAVEMAN et al., 2005; WILKINSON, 1997a).

De acordo com Wilkinson (1997a), em países em desenvolvimento, a relação entre padrão absoluto de renda e saúde não é totalmente esclarecida. Para o autor, não são as sociedades mais ricas, mas sim as mais igualitárias que possuem melhores níveis de saúde. Os membros dessas sociedades parecem compartilhar aspectos comuns de altos níveis de coesão social. Assim, muitas medidas de privação social, como renda absoluta, podem não estar correlacionadas com níveis de doença.

Ainda, no presente estudo, nem todas as medidas de renda absoluta estavam associadas ao desfecho quando submetidas à analise de regressão linear múltipla (Tabelas 5.6 a 5.8). Quando se procurou associação entre pobreza (privação) a partir dos diferenciais de linha de pobreza (variável "POB"), não se observou associação significante após o ajuste final do modelo tanto para os índices CPO-D (Tabela 5.6) como para a porcentagem de crianças livres de cárie (Tabela 5.7).

Embora alguns estudos tenham demonstrado associação quando utilizaram essa variável (BALDANI; NARVAI; ANTUNES, 2002; BALDANI; VASCONCELOS; ANTUNES, 2004), a abordagem da linha da pobreza tem sido duramente criticada por ser dicotômica, ignorando, assim, o fato de que a escala de condição social e econômica é, na verdade, contínua. Ademais, a noção de linha da pobreza é 
puramente econômica e ignora as várias dimensões da vida humana que compõem a "real" condição social, influenciada por valores econômicos, políticos, culturais, étnicos, religiosos, dentre outros (MOYSÉS, 2000; WILKINSON, 1997a, 1997b).

A respeito dessas limitações, muitos estudos têm usado padrões de desigualdades na distribuição de renda como efeito explicativo dos níveis de saúde na população (ANTUNES et al., 2002, 2004a; BALDANI; NARVAl; ANTUNES, 2002; BALDANI; VASCONCELOS; ANTUNES, 2004; PATTUSSI et al., 2001; PERES et al., 2003; WLKINSON, 1997a, 1997b; WILKINSON; BEZRUCHKA, 2002), suportando o fato de que a extensão das ineqüidades entre ricos e pobres influenciaria sensivelmente os padrões de saúde e doença.

Tem sido sugerido que as principais razões por que as sociedades mais igualitárias possuem melhores níveis de saúde se encontra no fato de essas sociedades serem socialmente mais coesas e com maior capacidade de suprir as necessidades de seus membros (WILKINSON, 1997a; WAGSTAFF; VAN DOOSLAER, 2000; BOING; KOVALESKI; ANTUNES, 2006; MULLER, 2002).

No presente estudo foi utilizado o coeficiente Gini para mensurar a desigualdade na distribuição de renda. Esse coeficiente tem sido amplamente utilizado na literatura para verificar sua associação com níveis de saúde da população (WAGSTAFF; VAN DOOSLAER, 2000), sendo seus valores associados com cárie dental em alguns estudos conduzidos no cenário nacional (ANTUNES et al., 2002; PATTUSSI et al., 2001).

Entretanto, os resultados do presente estudo não mostraram associação significante entre esse coeficiente e os índices CPO-D e porcentagem de crianças livres de cárie, tanto nas análises univariadas (Tabelas 5.3 e 5.4), como nas análises de regressão múltipla (Tabelas 5.6 e 5.7). Tal variável explicou apenas $7 \%$ dos 
valores do CPO-D (Tabela 5.6) e 8\% da variação na porcentagem de crianças livres de cárie em 2002-2003 (Tabela 5.7).

Outro estudo também não encontrou tal associação quando esses valores eram aferidos na população brasileira (PERES et al., 2003).

Uma explicação para esses resultados seria a baixa variação desse índice na população estudada. De acordo com a tabela 5.1 , pode-se verificar que, embora houvesse uma ampla variação na maioria dos indicadores socioeconômicos analisados, os valores do coeficiente de Gini apresentaram, de uma maneira geral, uma menor variação entre as capitais. Por exemplo, enquanto os valores de renda per capita variaram de $\mathrm{R} \$ 251,00$ a $R \$ 709,00$, apresentando um alto desvio-padrão $(153,75)$, os valores do coeficiente de Gini variaram de 0,57 a 0,68 , sendo que o desvio-padrão foi de 0,03 , com valores muito próximos entre os percentis (Tabela 5.1). Ou seja, as capitais analisadas possuíam, de um modo geral, um perfil muito similar no que se refere à distribuição de renda, o que dificulta a análise do efeito dessa variável nos níveis de saúde.

Tal fato foi discutido por Wilkinson (1997a, 1997b). De acordo com o autor, os valores de desigualdade na distribuição de renda possuem um efeito maior em áreas que contêm um saliente social heterogêneo. Em áreas ou entre populações nas quais os níveis de ineqüidades na distribuição de renda assumem valores mais homogêneos, o efeito de tal variável é menor ou mesmo desaparece quando controlado pela renda absoluta. Assim, mesmo entre populações em que os níveis de ineqüidades na distribuição de renda possam ser altos, mas apresentando baixa variação entre as unidades de análise, tais valores acabam sendo pouco relacionados com níveis de saúde porque a comparação entre estratos sociais é perdida. 
Ainda, as desigualdades de renda podem estar associadas a outras variáveis que também explicariam o desfecho. De acordo com a tabela 5.2, pode-se observar que os valores do coeficiente de Gini apresentaram correlação estatisticamente significante com variáveis educacionais como a taxa de analfabetismo infantil $(r=0,71 ; p<0,01)$ e a defasagem escolar média $(r=0,71 ; p<0,01)$; e com o IDI $(r=-0,56$; $p<0,01)$. Tais associações entre algumas medidas referentes ao desenvolvimento humano, sugerem que a desigualdade de distribuição de renda pode nem sempre ter um efeito direto nos níveis de cárie, mas sim refletir o efeito de outras variáveis relacionadas à doença (MULLER, 2002).

Outra abordagem utilizada freqüentemente nos estudos ecológicos em saúde bucal é a analise de Índices de Desenvolvimento Humano Sustentável, como o IDH e o IDI. No presente estudo pôde-se constatar uma correlação negativa entre o IDH e o CPO-D ( $r=-0,51 ; p<0,01)$, e correlação positiva entre o IDH e a porcentagem de crianças livres de cárie $(r=0,54 ; p<0,01)$ (Tabela 5.2). Essa variável manteve sua significância na análise de regressão múltipla, tanto considerando índice CPO-D como percentual de crianças livres de cárie, como desfechos (Tabelas 5.6 e 5.7).

Após a exclusão de um outlier representado pelo município de Boa Vista (IDH $(0,604)$, pôde-se observar que o modelo final incluindo a variável IDH foi responsável por $37 \%$ da variação dos valores do índice CPO-D (Tabela 5.6) e por $32 \%$ da variação na porcentagem de crianças livres de cárie (Tabela 5.7).

Resultados semelhantes foram encontrados por Antunes et al. (2004a, 2006), Baldani, Narvai e Antunes (2002), Hobdell et al.(2003), Moysés (2000) e Peres et al. (2003).

Capitais com maiores valores de desenvolvimento humano apresentaram menores índices CPO-D e maior porcentagem de crianças livres de cárie (Tabelas 
5.2, 5.6 e 5.7). Tais resultados suportam o fato de que as dimensões de desenvolvimento humano sustentável incluídas nesse índice são fortes indicadores da experiência de cárie nas populações, o que sugere que estratégias de promoção de saúde e controle da doença cárie requerem ações governamentais dinâmicas que atuem em diversos fatores relacionados aos níveis de desenvolvimento humano e social de determinadas áreas geográficas.

No presente estudo pôde-se observar uma correlação negativa entre o número de cirurgiões-dentistas inscritos no CRO de cada município (por 10.000 habitantes) e o índice CPO-D ( $r=-0,47$, tabela 5.2), significando que, quanto maior o CPO-D, menor a disponibilidade de profissionais. Esse achado confirma a premissa de Hart (2000) segundo a qual a disponibilidade de serviços médicos varia inversamente com a necessidade da população ("inverse care law"). Antunes et al. (2004b) encontraram resultados semelhantes quando tal análise era feita considerando o número de cirurgiões-dentistas que trabalhavam no setor privado do município.

A interpretação mais evidente para esse resultado seria a de que o maior número de cirurgiões-dentistas em um município contribui diretamente para um menor índice CPO-D. Porém, concordando com o que foi demonstrado por Nadanovsky e Sheiham (1995), essa associação não se mostrou significativa quando controlada por outros indicadores socioeconômicos, tanto no que se refere à experiência de cárie, quanto como um fator explicativo da variação dos níveis de CPO-D entre 1996 e 2002-2003 (Tabelas 5.6 e 5.8).

Peres et al. (2003) em estudo ecológico objetivando avaliar a associação entre diversos indicadores socioeconômicos e a distribuição de cárie dental em crianças de 5 a 6 anos de 129 municípios do estado de São Paulo, também 
verificaram resultados semelhantes. De acordo com os autores, a taxa de cirurgiõesdentistas municipais (por 10.000 habitantes) explicou apenas 11\% da variação da experiência de cárie da amostra, não sendo um fator significante quando controlado pelas demais variáveis de estudo.

Entretanto, há de se considerar que, no presente estudo, a taxa de cirurgiõesdentistas municipais foi mensurada utilizando os dados de profissionais inscritos no CRO do município. Assim, não é possível estimar a real quantidade de profissionais que realmente estão ativos no município, nem mesmo dimensões como qualidade de serviços ou número de procedimentos realizados.

Pôde-se observar uma correlação estatisticamente significante entre a porcentagem de distritos do município com a presença de flúor na água de abastecimento e a experiência de cárie (Tabela 5.2). No entanto a análise multivariada não incluiu no modelo final tal variável para nenhum dos desfechos considerados (Tabelas 5.6 a 5.8). Esse achado torna-se preocupante, principalmente considerando que essa variável é indicada como um dos fatores mais importantes para a redução na prevalência de cárie observada nos últimos anos no país (NARVAl et al., 2006).

Porém esses resultados devem ser observados com cautela. $O$ efeito benéfico da fluoretação da água de abastecimento é bem documentado em estudos de base populacional realizados no contexto brasileiro (ANTUNES et al., 2006; BALDANI; NARVAI; ANTUNES, 2002; NARVAl et al., 2006; PERES et al., 2003).

Além disso, Burt (2002) ressalta o fato de que a fluoretação da água de abastecimento não só contribui para uma melhora significativa nos índices de cárie dental, mas também pode ser considerada uma medida capaz de atenuar as disparidades em saúde entre diferentes estratos socioeconômicos. 
No presente estudo, essa variável foi mensurada utilizando a porcentagem de distritos municipais com água de abastecimento fluoretada, sendo que apenas uma pequena parcela de municípios não possuía esse benefício na totalidade de seus distritos (Tabela 5.1). Mesmo nesses municípios, não se pode descartar a possibilidade de as crianças estarem recebendo o benefício do flúor na escola ou mesmo de outras fontes das quais a família obtém água (ANTUNES et al., 2002; NARVAl et al., 2006).

Além disso, neste estudo não foi avaliado o tempo de fluoretação da água de abastecimento. Assim, considerando que o impacto desse benefício tem sido relacionado com o tempo de introdução dessa estratégia na população, um efeito maior dessa variável poderia estar sendo subestimado.

De acordo com os resultados expressos nas análises univariadas, observouse associação significante com indicadores de educação e a experiência de cárie dental (Tabelas 5.3 e 5.4). Porém tais indicadores perderam seus efeitos quando analisados conjuntamente com outras variáveis significantes após as análises de regressão múltipla (Tabelas 5.6 a 5.8). Tal efeito poderia ser questionado devido à inclusão desses parâmetros no modelo juntamente com indicadores de renda, os quais apresentaram colinearidade (Tabela 5.2). Entretanto, diferentes indicadores socioeconômicos não atuam de forma interrelacionada. Embora se possa observar uma determinada correlação, por exemplo, entre renda e indicadores de educação, essas medidas não devem ser analisadas em conjunto como covariáveis na análise de regressão. Ou seja, múltiplas medidas socioeconômicas podem ser incluídas em modelos de regressão sem problemas maiores em relação à colinearidade, desde que a estratificação seja considerada (BOING; KOVALESKI; ANTUNES, 2006; BRAVEMAN et al., 2005). 
Ambas as medidas de renda e educação podem influenciar a etiologia de muitos desfechos em saúde, em parte por diferentes maneiras. Educação pode ainda refletir uma série de características não-econômicas (conhecimento geral e auto-conhecimento em saúde, alfabetização, prestígio, capacidade de resolver problemas) com importantes efeitos na saúde. Assim, para muitos desfechos em saúde, educação deve ser considerada em adição e não em detrimento de outros fatores socioeconômicos como, por exemplo, a renda (BRAVEMAN et al., 2005).

Há de se considerar ainda que indicadores de educação - como, anos de escola, por exemplo - podem não capturar diferenças significantes em termos de qualidade no processo de aprendizado, o que não justificaria sua utilização como parâmetro substitutivo de outros indicadores socioeconômicos (BRAVEMAN et al., 2005).

Também foi objetivo deste estudo analisar a associação dos fatores socioeconômicos com o percentual de variação nos valores de CPO-D ocorrido nessas capitais durante os anos de 1996 e 2002-2003. Para que se pudesse realizar essa análise, os dados a respeito do CPO-D em crianças de 12 anos, de acordo com o levantamento de 2002-2003, foram comparados aos dados de um outro levantamento realizado em âmbito nacional no ano de 1996.

No Brasil, levantamentos epidemiológicos a respeito de saúde bucal vêm sendo realizados desde a década de 1980 e, embora apresentem diferenças estruturais em termos de delineamentos, seus resultados permitem análises que são úteis para explorar associações entre taxas de doenças ao longo do tempo e sua associação com determinantes contextuais (ANTUNES et al., 2006; NARVAl et al., 2006). 
A escolha de realizar uma comparação entre os levantamentos de 1996 e 2002-2003 foi devido às características desses levantamentos. A primeira delas refere-se ao fato de esses dois levantamentos terem sidos realizados em âmbito nacional. Embora o levantamento realizado em 1986 também tenha essa característica, seus resultados não poderiam gerar análises comparativas, pois só foram utilizadas 16 capitais na composição amostral, sem detalhamento das razões de exclusão de outras capitais representativas das macrorregiões brasileiras (OLIVEIRA, 2006). A segunda refere-se ao fato de que, tanto no levantamento de 1996 como no de 2002-2003, foram utilizadas todas as capitais nacionais, o que permite uma comparação direta dos municípios em dois diferentes momentos.

De acordo com os resultados apresentados nas tabelas 5.2 e 5.5, pôde-se observar que houve correlação estatisticamente significante entre a variação ocorrida nos valores de CPO-D entre os anos de 1996 e 2002-2003, e o percentual de crianças livres de cárie $(r=0,43 ; p<0,01)$ e experiência de cárie no último levantamento $(r=-0,60 ; p<0,01)$. Isso significa que as capitais com menores valores de CPO-D em 2002-2003 apresentaram um percentual maior de redução de cárie dental.

Ao analisarmos a associação entre os indicadores socioeconômicos e as variações ocorridas nos valores de CPO-D entre os diferentes levantamentos, pôdese verificar que apenas o coeficiente de Gini apresentou valores de correlação estatisticamente significantes $(r=-0,40 ; p<0,05)$, sendo que, na análise de regressão, o modelo que incluiu essa variável juntamente com os valores de CPO-D e porcentagem de crianças livres de cárie em 2002-2003, explicou aproximadamente $47 \%$ da redução ocorrida no período considerado (Tabela 5.8). 
Tais resultados sugerem que capitais com maiores níveis de eqüidades em temos de distribuição de renda apresentaram maiores níveis de redução de cárie dental, reforçando a necessidade de estratégias voltadas à redução das ineqüidades para melhorias em termos de saúde.

Concordando com Nadanovsky e Sheiham (1995), a taxa de cirurgiõesdentistas no município teve pouco efeito na variação encontrada no CPO-D entre o período analisado. De acordo com os resultados da análise de regressão linear simples, apenas 7\% da redução no CPO-D pôde ser explicada por essa variável.

Entretanto esses resultados devem ser analisados com cautela, principalmente no que se refere a associação não significantes encontradas entre variáveis importantes relacionadas à diminuição nos índices de cárie dental como é o caso do flúor, discutido anteriormente.

Neste estudo, procurou-se avaliar o efeito das condições socioeconômicas em um único período. Não foi realizada nenhuma análise de tendência desses indicadores. Assim, não foi verificado o efeito das mudanças desses fatores no desfecho, constituindo um viés, pois tais modificações poderiam explicar melhor as variações encontradas em termos de redução.

Dessa maneira, os resultados, no que se refere à redução, devem ser interpretados como hipóteses que necessitam ser testadas futuramente considerando tais variações e em populações com diferentes características, principalmente de diferentes portes populacionais e considerando outras faixas etárias.

Além disso, tem-se que considerar que, neste estudo, todas as análises foram realizadas através de um delineamento ecológico em um único nível. 
Os estudos de desigualdades sociais em saúde se viram beneficiados com a concepção de que delineamentos de base ecológica são modelos apropriados e não substitutos de estudos de base individual. Estudos utilizando tal delineamento são úteis para a análise de hipótese em níveis mais abrangentes e complexos de determinação, dando-se ênfase aos determinantes macro-contextuais em saúde, principalmente quando o isolamento de variáveis individuais não é possível.

No entanto, ao analisarmos os resultados de estudos ecológicos tem-se que considerar que nem sempre os resultados aferidos para a população refletem a experiência concreta de indivíduos ("falácia ecológica"). Porém, indivíduos em uma comunidade geralmente compactuam uma série comum de valores e normas, as quais têm um papel fundamental na formação de hábitos de saúde (WAGSTAFF, 2002). Ou seja, o ambiente pode expressar uma série de interações complexas entre seus indivíduos, fato que aproxima os estudos ecológicos da realidade na medida em que tenta entender essas interações (MOYSÉS; MOYSÉS, 2006). Assim, a famigerada "falácia ecológica" deve ser interpretada como um efeito resultante da agregação das variáveis que, por si só, não determina uma fonte de erro, mas sim uma característica metodológica própria desse tipo de estudo (MOYSÉS; MOYSÉS, 2006).

Ainda, como a atenção em saúde é um fenômeno coletivo, estudos de dados unicamente individualistas não são suficientes para expressar fenômenos comunitários ("falácia individualista") (MOYSÉS; MOYSÉS, 2006).

Há uma diferença cronológica entre o desfecho e as variáveis explicativas utilizadas neste estudo. As variáveis socioeconômicas foram coletadas de acordo com os dados do último censo realizado em âmbito nacional, no ano de 2000 (IBGE, 2001), enquanto que os índices de cárie dental foram coletados no último 
levantamento epidemiológico nacional realizado entre os anos de 2002 e 2003 (BRASIL, 2004). Tal diferença poderia ser considerada como um potencial viés neste estudo, pois as análises de regressão e os coeficientes de correlação calculados não consideram essa diferença temporal.

Entretanto, cárie dental requer um determinado tempo para seu desenvolvimento, e as condições socioeconômicas não sofrem modificações consideráveis dentro de uma mesma linha de tempo. Ainda, o exame realizado em 2003 detecta também o efeito cumulativo de cárie dental após o ano de 2000. Desse modo, crianças estudadas em 2003 nasceram antes do ano 2000 e estavam expostas aos fatores socioeconômicos municipais naquele período (PERES et al., 2003). Por essa razão, as variáveis socioeconômicas analisadas foram consideradas como uma possível estimação para os anos subseqüentes, e possíveis mudanças durante os três anos que as separam do último levantamento não inviabilizariam a realização das análises (ANTUNES et al., 2004a).

Embora a associação entre indicadores socioeconômicos e cárie dental esteja bem estabelecida na literatura, este estudo traz novos pontos de discussão.

Primeiramente porque se contemplaram na análise todas as capitais brasileiras, o que permite uma avaliação de municípios com diferentes estruturações em termos de sociedade e, mesmo que todos sejam classificados como municípios de grande porte, discrepâncias regionais importantes podem ser observadas.

Também foram utilizados diferentes indicadores socioeconômicos como possíveis determinantes de cárie dental aos 12 anos de idade. A inclusão de tais indicadores ocorreu devido à necessidade de avaliar um número de variáveis que expressassem diferentes dimensões às quais a população está exposta. De acordo com Braveman et al. (2005), essa opção deve ser preferível em estudos que se 
destinam à avaliação de fatores socioeconômicos em saúde, pois possibilitam uma avaliação mais dinâmica das relações sociais em saúde.

Entretanto, deve-se considerar que esses indicadores expressam apenas uma aproximação da realidade social de uma população e, mesmo que sejam uma opção amplamente utilizada em estudos epidemiológicos, não conseguem por si só capturar dimensões importantes principalmente de como se dá sua complexa relação causal com desfechos em saúde. Estudos objetivando entender os mecanismos causais, bem como o efeito da modificação desses indicadores nos níveis de saúde devem ser realizados na medida em que contribuem para a implementação de políticas públicas efetivas de ação nesses determinantes.

Além disso, este estudo utilizou dados oficiais de dois levantamentos para avaliar a associação dos fatores socioeconômicos no percentual de redução de cárie dental observado no período considerado. Embora comparações entre levantamentos nacionais tenham sido realizadas na literatura, as análises empregadas neste estudo contribuem para uma visualização mais acurada das variações na experiência de cárie dental, pois permitiram uma comparação direta dos mesmos municípios em dois períodos distintos de tempo. Considerando que cada capital é uma representação de estruturas históricas, sociais e culturais de uma região, a análise realizada acaba contemplando, assim, um retrato geral do país.

De acordo com a metodologia utilizada, pôde-se observar que a estrutura social e econômica a que uma população está exposta age como um fator determinante nas condições de saúde. Tal constatação torna-se importante para a população, pois repercute diretamente na necessidade de implementação de programas de prevenção e controle da doença, bem como a orientação de políticas governamentais que visem à atuação macrossetoriais nos reais determinantes de 
cárie dental na população, como a formação de ambientes suportivos que permitam que as escolhas saudáveis sejam naturalmente feitas pelos indivíduos. 


\section{CONCLUSÃO}

De acordo com os resultados, pôde-se concluir que as capitais com melhores perfis socioeconômicos apresentaram uma menor experiência de cárie dental, indicando que estratégias públicas de saúde devem ser direcionadas para esses determinantes. Os resultados também sugerem que redução de cárie dental demanda ações governamentais amplas que busquem diminuir as ineqüidades socioeconômicas. 


\section{REFERÊNCIAS ${ }^{1}$}

Almeida-Filho N, Rouquayrol MZ. Introdução à epidemiologia. $1^{\text {a }}$ ed. Rio de Janeiro: Medsi; 2002. cap. 4, p. 65-78.

Amstutz RD, Rozier RG. Community risk indicators for dental caries in school children: an ecologic study. Community Dent Oral Epidemiol 1995;23(3):129-37.

Antunes JLF. Mortalidade por câncer e desigualdade social em São Paulo [Tese de Livre-Docência] São Paulo: Faculdade de Odontologia da USP; 2005.

Antunes JLF, Jahn GM, de Camargo MA. Increasing inequalities in the distribution of dental caries in the Brazilian context. Community Dent Health 2004a;22(2):94-100.

Antunes JLF, Narvai PC, Nugent ZJ. Measuring inequalities in the distribution of dental caries. Community Dent Oral Epidemiol 2004b;32(1):41-8.

Antunes JLF, Trigueiro VA, Terra SP. O campo da odontologia social: pesquisas indexadas no Medline entre 1997-1998. Odontol e Soc 1999;1(1):31-4.

Antunes JLF, Peres MA, Mello TR, Waldman EA. Multilevel assessment of determinants of dental caries experience in Brazil. Community Dent Oral Epidemiol 2006;34(2):146-52.

Antunes JLF, Frazão P, Narvai PC, Bispo CM, Pegoretti T. Spatial analysis to identify differentials in dental needs by area-based measures. Community Dent Oral Epidemiol 2002;30(2):133-42.

Antunes JLF, Junqueira SR, Frazão P, Bispo CM, Pegoretti T, Narvai PC. City-level gender differentials in the prevalence of dental caries and restorative dental treatment. Health Place 2003;9(3):231-9.

Baldani MH; Narvai PC; Antunes JLF. Cárie dentária e condições sócio-econômicas no Estado do Paraná, Brasil, 1996. Cad Saúde Públ 2002;18(3):755-63.

\footnotetext{
${ }^{1}$ De acordo com estilo Vancouver. Abreviatura de periódicos segundo Bases de Dados MEDLINE.
} 
Baldani MH, Vasconcelos AGG, Antunes JLF. Avaliação do índice CPO-D com indicadores sócio-econômicos e de provisão de serviços odontológicos no estado do Paraná, Brasil. Cadernos de Saúde Pública 2004;20(1):143-52.

Bezruchka S. Income inequality and population health. Hierarchy and health are related. BMJ 2002;324(7343):978.

Blakely T, Kawachi I, Atkinson J, Fawcett J. Income and mortality: the shape of the association and confounding New Zealand Census-Mortality Study, 1981-1999. Int J Epidemiol 2004;33(4):874-83.

Boing AF, Kovaleski DF, Antunes JLF. Medidas de condições socioeconômicas em estudos epidemiológicos de saúde bucal. In: Antunes JLF, Peres MA. Epidemiologia da saúde bucal. $1^{a}$ ed. Rio de Janeiro: Guanabara Koogan; 2006. cap. 1, parte 2, p. 235-48.

Boing AF, Peres MA, Kovaleski DF, Zange SE, Antunes JLF. Estratificação sócioeconômica em estudos de epidemiologia de cárie dental e doenças periodontais: características da produção da década de 90. Cad Saúde Públ 2005;21(3):673-8.

Bönecker M, Marcenes W, Sheiham A. Caries reductions between 1995, 1997 and 1999 in preschool children in Diadema, Brazil. Int J Paediatr Dent 2002;12(3):18388.

Brasil. Ministério da Saúde. Coordenação Nacional de Saúde Bucal. Condições de saúde bucal da população brasileira. Resultados principais. Brasília: Ministério da Saúde; 2004. Disponível em: URL:

http://dtr2001.saude.gov.br/editora/produtos/livros/zip/04 0347 M.zip [10 jan. 2005].

Braveman PA, Cubbin C, Egerter S, Chideya S, Marchi KS, Metzler M, et al. Socioeconomic status in health research: one size does not fit all. J Am Med Assoc 2005;294(22):2879-88.

Buck C, Slopis H, Najera E, Terris M. El desafio de la epidemiologia. Problemas y lecturas seleccionadas. $1^{\mathrm{a}}$ ed. Washington: Organizacion Panamericana de la Salud; 1989.

Burt BA. Concepts of risk in dental public health. Community Dent Oral Epidemiol 2005;33(4):240-7.

Burt BA. Fluoridation and social equity. J Public Health Dent 2002;62(4):195-200. 
Cameron D, Jones IG. John Snow, the Broad Street pump and modern epidemiology. Int J Epidemiol 1983;12(4):393-6.

CFO. Disponível em: URL: http://www.cfo.org.brl. [20 jul. 2006].

Cockerham WC, Hattori H, Yamori Y. The social gradient in life expextancy: the contrary case of Okinawa in Japan. Soc Sci Med 2000;51(1):115-22.

Dahlgren G, Whitehead M. Policies and strategies to promote social equality in health. Copenhagen: WHO/Regional office for Europe;1992.

Daly B, Watt R, Batchelor P, Treasure E. Essential dental public health. 1st ed. Oxford: Oxford University Press; 2002.

Egri M, Gunay O. Association between some educational indicators and dental caries experience of 12-year-old children in developing countries: an ecological approach. Community Dent Health 2004;21(3):227-9.

Ellwood RP, O'Mullane DM. Identification of areas with high levels of untreated dental caries. Community Dent Oral Epidemiol 1996;24(1):1-6.

Evans A. Causation and disease. A chronological journey. New York, Plenum Medical Book Company; 1993.

Fernandes LS, Peres MA. Associação entre atenção básica em saúde bucal e indicadores socioeconômicos municipais. Rev Saúde Pública 2005;39(6):930-6.

Gratrix D, Holloway PJ. Factors of deprivation associated with dental caries in young children. Community Dent Health 1994;11(2):66-70.

Gravelle $\mathrm{H}$. How much of the relation between population mortality and unequal distribution of income is a statistical artefact? BMJ 1998;316(7128):382-5.

Gordis L. Epidemiologia. $2^{\mathrm{a}}$ ed. Trad. de Cláudia Adelino Espanha. Rio de Janeiro: Revinter; 2004.

Hart JT. Commentary: Three decades of the inverse care law. BMJ 2000;320(1):18-9. 
Hausen H. Caries prediction--state of the art. Community Dent Oral Epidemiol 1997;25(1):87-96.

Hill AB. The environment and disease: association or causation? Proc R Soc Med 1965;58:295-300.

Hobdell MH, Oliveira ER, Bautista R, Myburgh NG, Lalloo R, Narendran S, et al. Oral diseases and socio-economic status (SES). Br Dent J 2003;194(2):91-6.

IBGE. Disponível em: URL: http://www.ibge.gov.br/. [20 jul. 2006].

IBGE. Censo demográfico 2000. Características da população e dos domicílios. Resultados do universo. Rio de Janeiro; 2001.

IPEA. Disponível em: URL://http:www.ipea.gov.br/ [12 jun 2006].

Keyes $\mathrm{PH}$. Recent advances in dental caries research bacteriology. Int Dent $\mathrm{J}$ 1962;12(1):443-64.

Khoury MJ, Millikan R, Little J, Gwinn M. The emergence of epidemiology in the genomics age. Int J Epidemiol 2004;33(5):936-44.

Krieger N. Sticky webs, hungry spiders, buzzing flies, and fractal metaphors: on the misleading juxtaposition of "risk factor" versus "social" epidemiology. J Epidemiol Community Health 1999;53(4):678-80.

Krieger N. Theories for social epidemiology in the 21st century: an ecosocial perspective. Int J Epidemiol 2001;30(4): 668-77.

Kumar JV, Wadhawan S. Targeting dental sealants in school-based programs: evaluation of an approach. Community Dent Oral Epidemiol 2002;30(3):210-5.

Locker D. Deprivation and oral health: a review. Community Dent Oral Epidemiol 2000;28(3):161-9.

Locker D, Ford J. Using area-based measures of socioeconomic status in dental health services research. J Public Health Dent 1996;56(2):69-75. 
Marcenes W, Bönecker M. Aspectos epidemiológicos e sociais das doenças bucais. In: Buischi YP. Promoção de saúde na clínica odontológica. $1^{a}$ ed. São Paulo: Artes Médicas; 2000. cap. 4, p. 75-98.

Marcenes WS, Sheiham A. The relationship between work stress and oral health status. Soc Sci Med 1992;35(12):1511-20.

Mackenbach JP. Income inequality and population health. BMJ 2002;324(7328):1-2.

Mackenbach JP, Kunst AE, Cavelaars AE, Groenhof F, Geurts JJ. Socioeconomic inequalities in morbidity and mortality in western Europe. The EU Working Group on Socioeconomic Inequalities in Health. Lancet 1997;349(9066):1655-9.

MacMahon B, Pugh TF. Epidemiology principles and methods. $1^{\text {st }}$ ed. Boston: Brown and Company; 1970. cap. 2, p. 17-27.

Moysés, SJ. Desigualdades em saúde bucal e desenvolvimento humano: um ensaio em preto, branco e alguns tons de cinza. Rev Bras Odontol Saude Coletiva 2000;1(1):7-17.

Moysés SJ, Moysés ST. Diferentes abordagens dos estudos epidemiológicos- do individual ao coletivo. In: Antunes JLF, Peres MA. Epidemiologia da saúde bucal. $1^{\text {a }}$ ed. Rio de Janeiro: Guanabara Koogan; 2006. cap. 4, parte 2, p. 269- 78.

Moysés ST, Rodrigues CS. Ambientes saudáveis: uma estratégia de promoção de saúde bucal em crianças. In: Bönecker M, Sheiham A. Promovendo saúde bucal na infância e adolescência: conhecimentos e práticas. $1^{\text {a }}$ ed. São Paulo: Santos; 2004. cap. 5, p. 81-92.

Muirhead V, Marcenes W. An ecological study of caries experience, school performance and material deprivation in 5-year-old state primary school children. Community Dent Oral Epidemiol 2004;32(4):265-70.

Muller A. Education, income inequality, and mortality: a multiple regression analysis. BMJ 2002;324(7328):23-5.

Nadanovsky P, Sheiham A. Relative contribution of dental services to the changes in caries levels of 12-year-old children in 18 industrialized countries in the 1970s and early 1980s. Community Dent Oral Epidemiol 1995;23(6):331-9. 
Nadanovsky P, Luiz RR, Costa AJL. Causalidade em saúde bucal. In: Luiz RR, Costa AJL, Nadanovsky P. Epidemiologia e bioestatística na pesquisa odontológica. 1a ed. Rio de Janeiro: Atheneu; 2005. cap. 4, parte 1, p. 71- 87.

Narvai PC, Frazão P, Roncalli AG, Antunes JLF. Cárie dentária no Brasil: declínio, iniqüidade e exclusão social. Rev Panam Salud Publica 2006;19(6):385-93.

Newton JT, Bower EJ. The social determinats of oral health: new approaches to conceptualizing and researching complex causal networks. Community Dent Oral Epidemiol 2005;33(1):25-34.

Oliveira AGRC. Levantamentos epidemiológicos em saúde bucal no Brasil. In: Antunes JLF, Peres MA.Epidemiologia da saúde bucal. $1^{\text {a }}$ ed. Rio de Janeiro : Guanabara Koogan; 2006. cap. 3, parte 1, p. 32- 48.

Pattussi MP, Hardy R, Sheiham A. The potential impact of neighborhood empowerment on dental caries among adolescents. Community Dent Oral Epidemiol 2006;34(5):344-50.

Pattussi MP, Marcenes W, Croucher R, Sheiham A. Social deprivation, income inequality, social cohesion and dental caries in Brazilian school children. Soc Sci Med 2001;53(7):915-25.

Pearce N. A short introduction to epidemiology. $2^{\text {nd }}$ ed. Wellington: Massey University Press; 2005.

Peres MA, Peres KG, Antunes JL, Junqueira SR, Frazao P, Narvai PC. The association between socioeconomic development at the town level and the distribution of dental caries in Brazilian children. Rev Panam Salud Publica 2003;14(3):149-57.

Petersen PE. Sociobehavioural risk factors in dental caries - international perspectives. Community Dent Oral Epidemiol 2005;33(4):274-9.

PNUD: Disponível em URL: http://pnud.org.br/ [14 jun 2006].

Roncalli AG. Levantamento epidemiológico em saúde bucal $-1^{\text {a }}$ etapa - Cárie dental, 1996. Relatório Paralelo, 1998. Disponível em: URL: http://angelonline.cjb.net/ [10 dez 2004]. 
Rose G. The strategy of preventive medicine. 2nd ed. Oxford: Oxford University Press; 1993.

Rose G. Sick individuals and sick populations. Int J Epidemiol 1985;14(1):32-8.

Rothman KJ. Causes. Am J Epidemiol 1976;104(6):587-92.

Rothman KJ, Greenland S. Causation and causal inference in epidemiology. Am J Public Health 2005;95(Suppl 1):S144-50.

Sanders AE, Slade GD, Turrell G, Spencer JA, Marcenes W. The shape of the socioeconomic-oral health gradient: implications for theoretical explanations. Community Dent Oral Epidemiol 2006;34(4):310-9.

Susser M, Susser E. Choosing a future for epidemiology: I. Eras and paradigms. Am J Public Health 1996a;86(5):668-73.

Susser M, Susser E. Choosing a future for epidemiology: II. From black box to Chinese boxes and eco-epidemiology. Am J Public Health 1996b;86(5):674-7.

Thygesen LC, Andersen GS, Andersen H. A philosophical analysis of the Hill criteria. J Epidemiol Community Health 2005;59(6):512-6.

UNICEF. Disponível em URL: http://www.unicef.org.br/. [20 jul. 2006].

Wagstaff A. Poverty and health sector inequalities. Bull World Health Organ 2002;80(2):97-105.

Wagstaff A, van Doorslaer E. Income inequality and health: what does the literature tell us? Annu Rev Public Health 2000;21:543-67.

Wagstaff A, Bustreo F, Bryce J, Claeson M. Child health: reaching the poor. Am J Public Health 2004;94(5):726-36.

Watt $\mathrm{R}$, Sheiham $\mathrm{A}$. Inequalities in oral health: a review of the evidence and recommendations for action. Br Dent J 1999;187(1):6-12. 
WHO. Oral health surveys, basic methods. $4^{\mathrm{a}}$ ed. Geneva: World Health Organization; 1997.

Wilkinson R, Bezruchka S. Income inequality and population health. Better measures of social differentiation and hierarchy are needed. BMJ 2002;324(7343):978.

Wilkinson RG. Comment: income, inequality, and social cohesion. Am J Public Health 1997a;87(9):1504-6.

Wilkinson RG. Socioeconomic determinants of health. Health inequalities: relative or absolute material standards? BMJ 1997b;314(7080):591-5. 
APÊNDICE A - Quadro comparativo de estudos ecológicos nacionais que avaliaram associação entre cárie dental e determinantes socioeconômicos.

\begin{tabular}{|c|c|c|c|c|}
\hline Autor & Local & Desfechos & Variáveis analisadas & Variáveis associadas/Resultados \\
\hline $\begin{array}{l}\text { Patussi et } \\
\text { al.,(2001) }\end{array}$ & DF & $\begin{array}{l}\text { - CPO-D (12 anos); } \\
\text { - \% livres de cárie } \\
\text { (LC) }\end{array}$ & $\begin{array}{l}\text { - Coesão social; privação social; privação material; } \\
\text { Gini. }\end{array}$ & $\begin{array}{l}\text { a } \underline{\text { CPO-D: }} \text { : } \\
\text { 1) Gini e escolaridade }\left(R^{2}=0,76\right) \text {; } \\
\text { 2) Gini }\left(R^{2}=0,31\right) \\
\text { a } L C \text { : } \\
\text { 1) Gini e escolaridade }\left(R^{2}=0,44\right) \text {; } \\
\text { 2) Gini }\left(R^{2}=0,49\right)\end{array}$ \\
\hline $\begin{array}{l}\text { Antunes et } \\
\text { al. (2002) }\end{array}$ & $\begin{array}{l}\text { Cidade } \\
\text { de SP }\end{array}$ & $\begin{array}{l}\text { - ceo-d e CPO-D (5 e } \\
12 \text { anos); } \\
\text { - índice de cuidados } \\
\text { odontológicos }\end{array}$ & $\begin{array}{l}\text { - Aglomeração domiciliar; } \\
\text { - Renda familiar média; } \\
\text { - Gini; } \\
\text { - Fluoretação e acesso à rede de abastecimento; } \\
\text { - Taxa de desemprego }\end{array}$ & $\begin{array}{l}\text { b renda }(-0,28) \text {; aglomeração } \\
(0,72) \text {; desemprego }(0,27) \text {; Gini } \\
(0,40)\end{array}$ \\
\hline $\begin{array}{l}\text { Baldani et } \\
\text { al. (2002) }\end{array}$ & PR & - CPO-D (12 anos) & $\begin{array}{l}\text { - IDH, IDI, IS, ICV } \\
\text { - Renda familiar média; índice de Theil; renda } \\
\text { insuficiente; } \\
\text { - Aglomeração domiciliar; ligação com água tratada e } \\
\text { esgoto; } \\
\text { - Anafalbetismo em adultos; crianças sem escolas; } \\
\text { defasagem escolar; criança que trabalha }\end{array}$ & $\begin{array}{l}\text { Através de análise de regressão } \\
\text { linear simples,todas as variáveis } \\
\text { apresentaram correlação } \\
\text { significante com variação no CPO- } \\
\text { D }\end{array}$ \\
\hline
\end{tabular}

continua.. 
continuação...

\begin{tabular}{|c|c|c|c|c|}
\hline Autor & Local & Desfechos & Variáveis analisadas & Variáveis associadas/Resultados \\
\hline $\begin{array}{l}\text { Peres et al. } \\
(2003)\end{array}$ & SP & $\begin{array}{l}\text { - ceo-d (5-6 anos) } \\
\text { - índice de cuidados } \\
\text { odontológicos (“care } \\
\text { index") }\end{array}$ & $\begin{array}{l}\text { - Socioeconômicas: renda; renda insuficiente; } \\
\text { coeficiente Gini; taxa de anafalbetismo; IDH; IDI } \\
\text { - Água e serviços: presença de flúor; dentistas por } \\
\text { habitantes; dentistas no serviço público; horas } \\
\text { trabalhadas no serviço público }\end{array}$ & $\begin{array}{l}\text { a ceo-d: } \\
\text { IDI, taxa de anafalbetismo }\left(R^{2}=0,49\right) \\
\text { a "care index": } \\
\text { IDI }\left(R^{2}=0,32\right)\end{array}$ \\
\hline $\begin{array}{l}\text { Baldani et } \\
\text { al. (2004) }\end{array}$ & PR & - CPO-D (12 anos) & $\begin{array}{l}\text { - Renda familiar média; índice de Theil; renda } \\
\text { insuficiente; } \\
\text { - Aglomeração domiciliar; ligação com água tratada e } \\
\text { esgoto; } \\
\text { - Anafalbetismo em adultos; crianças sem escolas; } \\
\text { defasagem escolar; Dentistas inscritos no CRO; N }{ }^{\circ} \\
\text { consultórios odontológicos }\end{array}$ & $\begin{array}{l}\text { Modelo 1: } \\
\text { Renda insuficiente e dentistas por } \\
\text { habitantes }\left(R^{2}=12,5 \%\right) ; \\
\text { a Modelo 2 (incluindo flúor na água de } \\
\text { abastecimento): } \\
\text { renda insuficiente e \% da população } \\
\text { com água fluoretada }\left(R^{2}=12,7 \%\right)\end{array}$ \\
\hline $\begin{array}{l}\text { Antunes et } \\
\text { al. (2004b) }\end{array}$ & SP & $\begin{array}{l}\text { - CPO-D (12 anos); } \\
\text { - Gini para } \\
\text { distribuição de cárie }\end{array}$ & $\begin{array}{l}\text { - Flúor e acesso a rede de abastecimento de água } \\
\text { - IDH, IDI, taxa de anafalbetismo, anos de estudo } \\
\text { - Provisão de serviços odontológicos }\end{array}$ & $\begin{array}{l}\text { a ceo-d: } \\
\text { IDI, taxa de anafalbetismo }\left(R^{2}=0,49\right) \\
\text { a "care index": } \\
\text { IDI }\left(R^{2}=0,32\right) \text { estudo e procedimentos } \\
\text { preventivos }\left(R^{2}=0,57\right) ; \\
\text { 2) anos de estudo, procedimentos } \\
\text { realizados na rede pública e } n^{\circ} \text { de } \\
\text { dentistas no serviço público }\left(R^{2}=0,60\right)\end{array}$ \\
\hline
\end{tabular}

continua... 
conclusão

\begin{tabular}{|c|c|c|c|c|}
\hline Autor & Local & Desfecho & Variáveis analisadas & Variáveis associadas/resultados \\
\hline $\begin{array}{l}\text { Antunes et } \\
\text { al. (2004a) }\end{array}$ & SP & $\begin{array}{l}\text { - CPO-D (12 anos); } \\
\text { - Desigualdade na } \\
\text { distribuição de cárie; } \\
\text { - Severidade de } \\
\text { cárie. }\end{array}$ & $\begin{array}{l}\text { - IDH, IDI, taxa de anafalbetismo infantil, renda } \\
\text { insuficiente } \\
\text { - Provisão de serviços odontológicos }\end{array}$ & $\begin{array}{l}\text { Análise de correlação linear } \\
\text { (coeficiente de correlação de } \\
\text { Pearson), demonstrou associação } \\
\text { entre os valores de CPO-D e } \\
\text { melhores índices de desenvolvimento } \\
\text { municipais, acesso à água fluoretada } \\
\text { e provisão de serviços }\end{array}$ \\
\hline $\begin{array}{l}\text { Antunes et } \\
\text { al. (2006) }\end{array}$ & Brasil & $\begin{array}{l}\text { - CPO-D (12 anos) } \\
\text { - "care index" } \\
\text { - Prevalência de } \\
\text { dentes cariados }\end{array}$ & $\begin{array}{l}\text { - Sexo, grupo étnico, localização e tipo de escola, IDH, } \\
\text { acesso à água tratada e presença de água fluoretada } \\
\text { nos últimos } 5 \text { anos }\end{array}$ & $\begin{array}{l}{ }^{c} \text { Prevalência de dentes cariados: } \\
{ }^{c-1} \text { Nível individual: Gênero feminino } \\
(\mathrm{OR}=1,1 ; \mathrm{IC} 95 \%: 1,0-1,1) \text {; raça negra } \\
(\mathrm{OR}=1,6 ; \mathrm{IC} 95 \%: 1,5-1,7) \text {; escolas } \\
\text { rurais }(\mathrm{OR}=1,9 ; \mathrm{IC} 95 \%: 1,0-1,1) ; \\
\text { escolas públicas (OR=1,7;IC95\%:1,6- } \\
1,9) ; \\
{ }^{c-2} \text { Nível comunitário: flúor; } \% \\
\text { domicílios ligados à rede de àgua; } \\
\text { IDH. }\end{array}$ \\
\hline
\end{tabular}

Análise de regressão linear múltipla;

${ }^{\mathrm{b}} \mathrm{SAR}$;

${ }^{c}$ Análise em Multinível: ${ }^{c-1}$ Regressão logística; ${ }^{c-2}$ Regressão linear múltipla;

$\mathrm{R}^{2}$ : Coeficiente de determinação ajustado; OR: odds ratio (IC: intervalo de confiança);

IDH: Índice de desenvolvimento Humano;

IDI: Índice de desenvolvimento Infantil;

IS: Índice de salubridade;

ICV: Índice de condições de Vida. 
APÊNDICE B - Quadro com as principais características metodológicas do Projeto SBBrasil 2003 (Adaptado de OLIVEIRA, 2006)

\begin{tabular}{|l|l|}
\hline Item & Descrição \\
\hline Grupos etários pesquisados & -18 a 36 meses \\
& -5 anos \\
& -15 a 19 anos \\
& -35 a 44 anos \\
& -65 a 74 anos \\
\hline Problemas pesquisados e informações obtidas & - Cárie dentária e necessidades de tratamento \\
& - Doença periodontal \\
& - Fluorose \\
& - Oclusopatias \\
& - Lesões bucais \\
& - Informações socioeconômicas, de acesso a \\
& serviços e de autopercepção em saúde bucal \\
\hline Pré-estratificação & - Macrorregiões brasileiras e porte populacional \\
\hline Pontos de coleta de dados & - Escolas e pré-escolas para 5 e 12 anos \\
& - Para adolescentes, adultos e idosos, os \\
& exames foram realizados em domicílios, tendo \\
& as quadras urbanas e/ou vilas rurais e os \\
& setores censitários como Unidades Amostrais \\
& Secundárias. \\
\hline Tamanho da amostra & - Aproximadamente 108 mil indivíduos \\
& examinados, uma média próxima de 500 por \\
& município. \\
\hline Treinamento e calibração & - Realizado para cada equipe local, por \\
& instrutores treinados pelos coordenadores \\
& regionais. \\
\hline & - Cálculo da concordância percentual e \\
& coeficiente Kappa para cada par de \\
& examinadores \\
\hline &
\end{tabular}


APÊNDICE C - Gráficos de dispersão entre CPOD e cada uma das variáveis explicativas e respectivas curvas suavizadas pelo método cubic spline
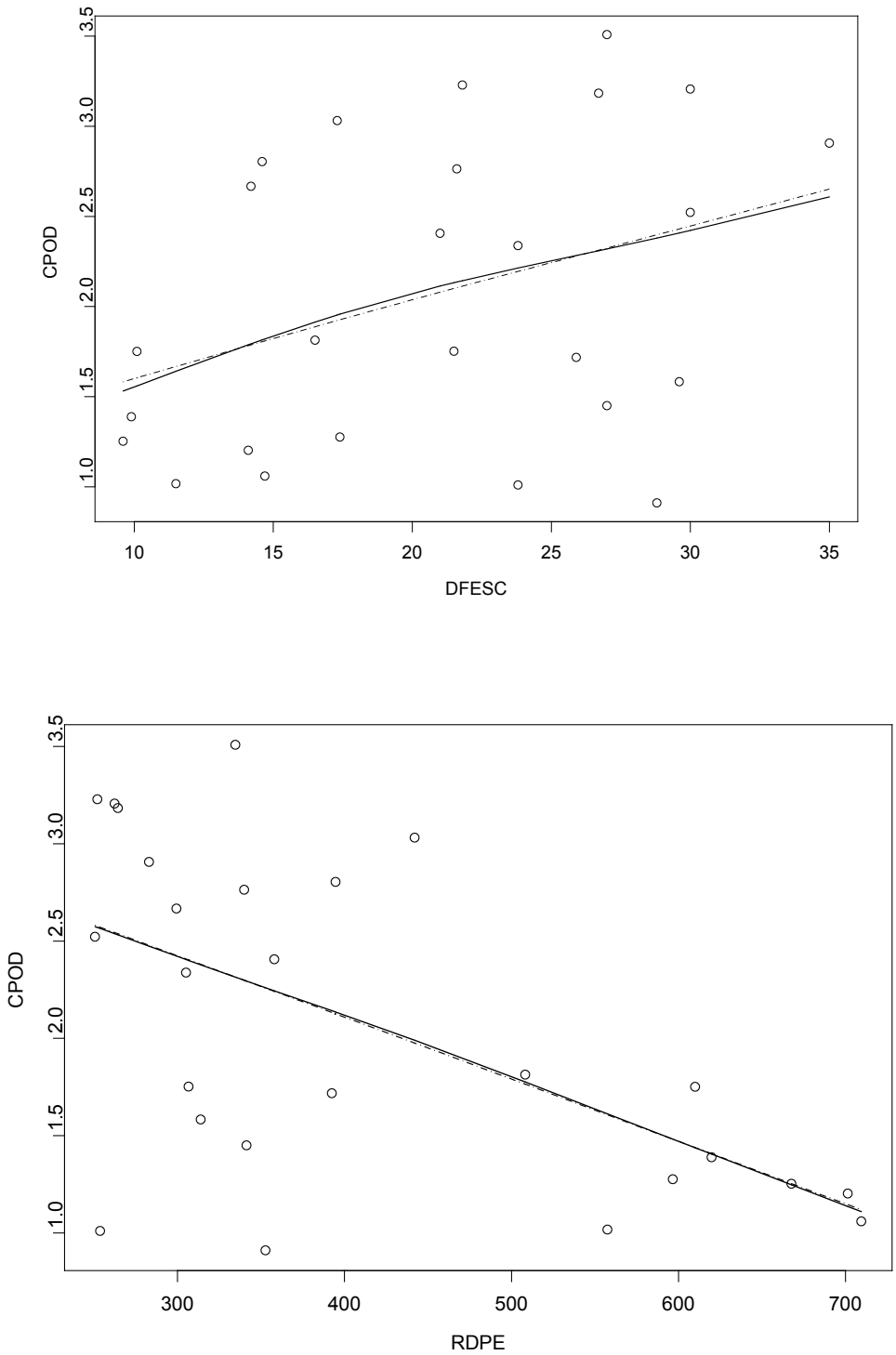

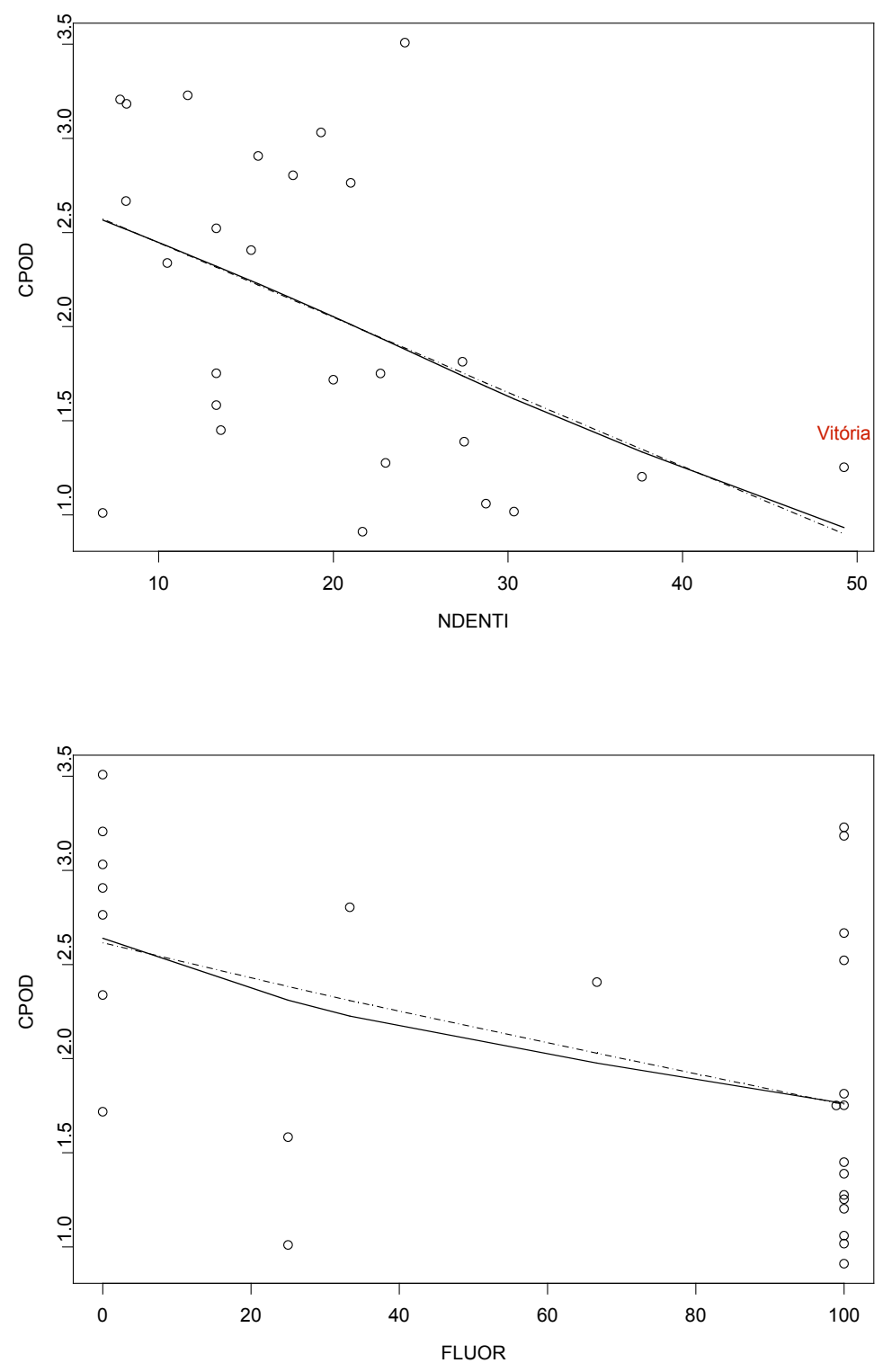


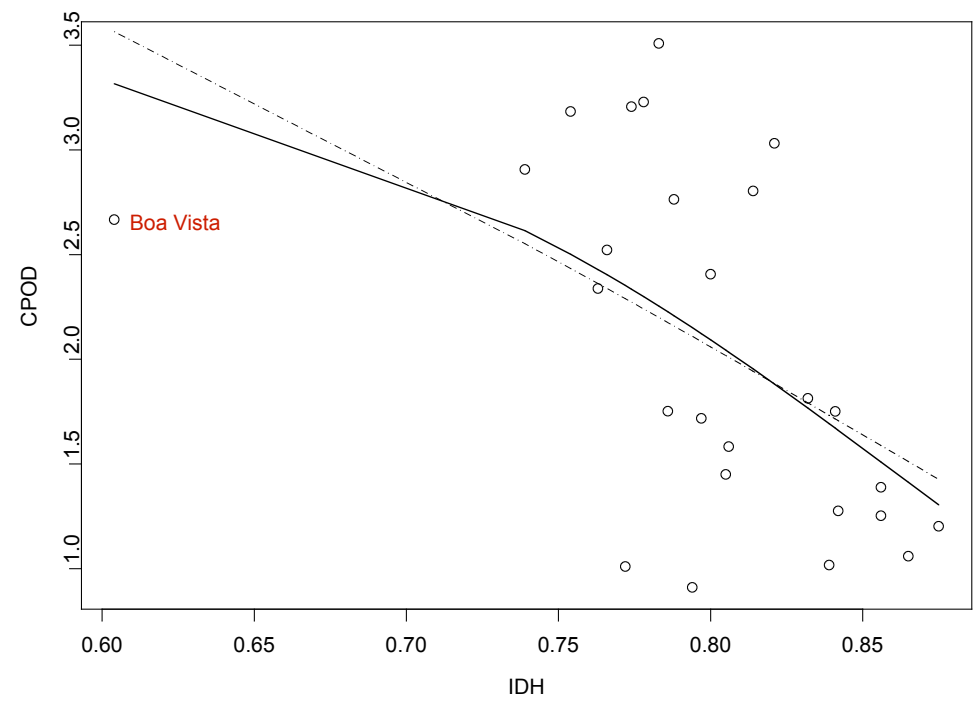


APÊNDICE D - Gráfico de dispersão entre porcentagem de crianças livres de cárie e cada uma das variáveis explicativas e respectivas curvas suavizadas pelo método cubic spline
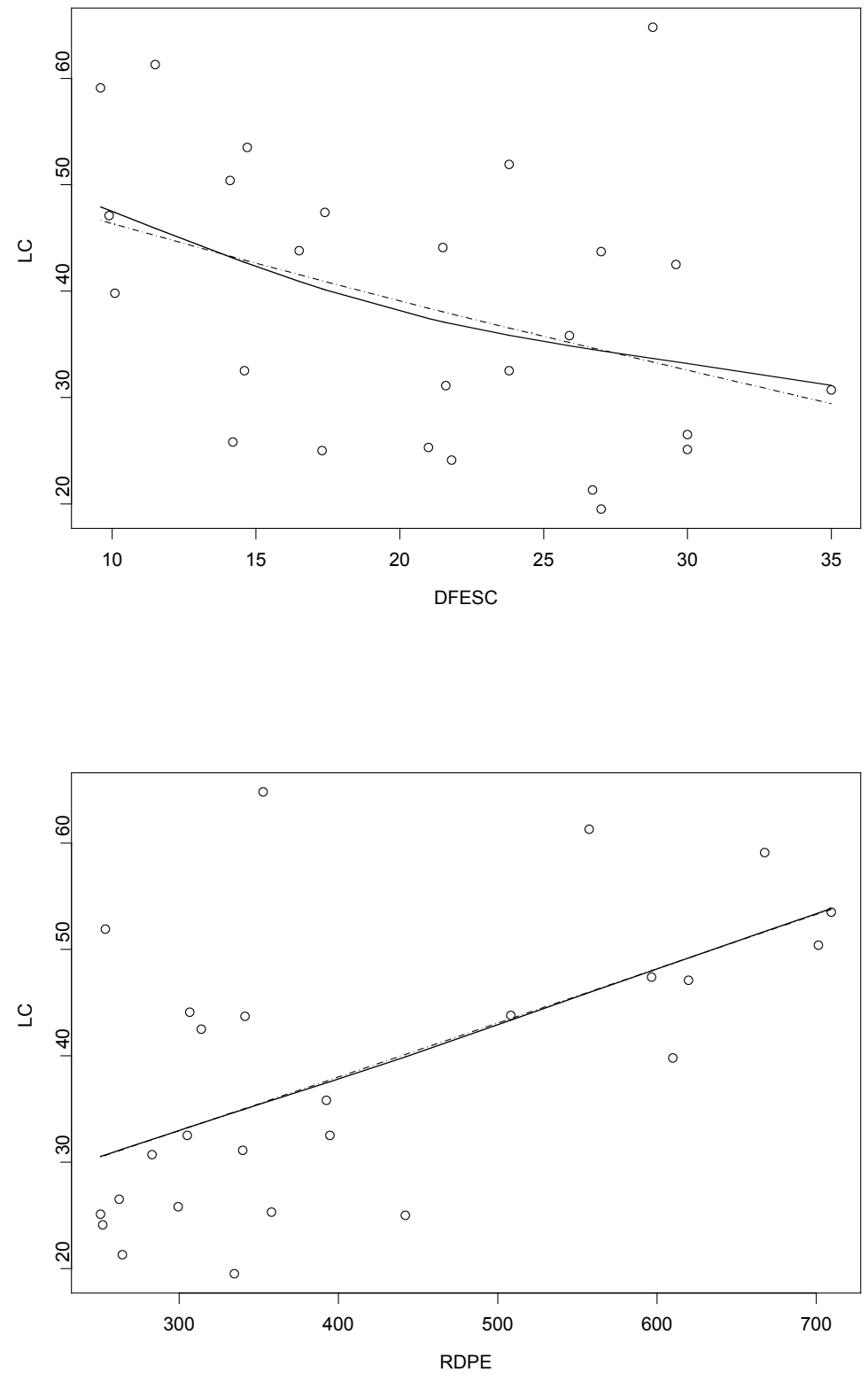

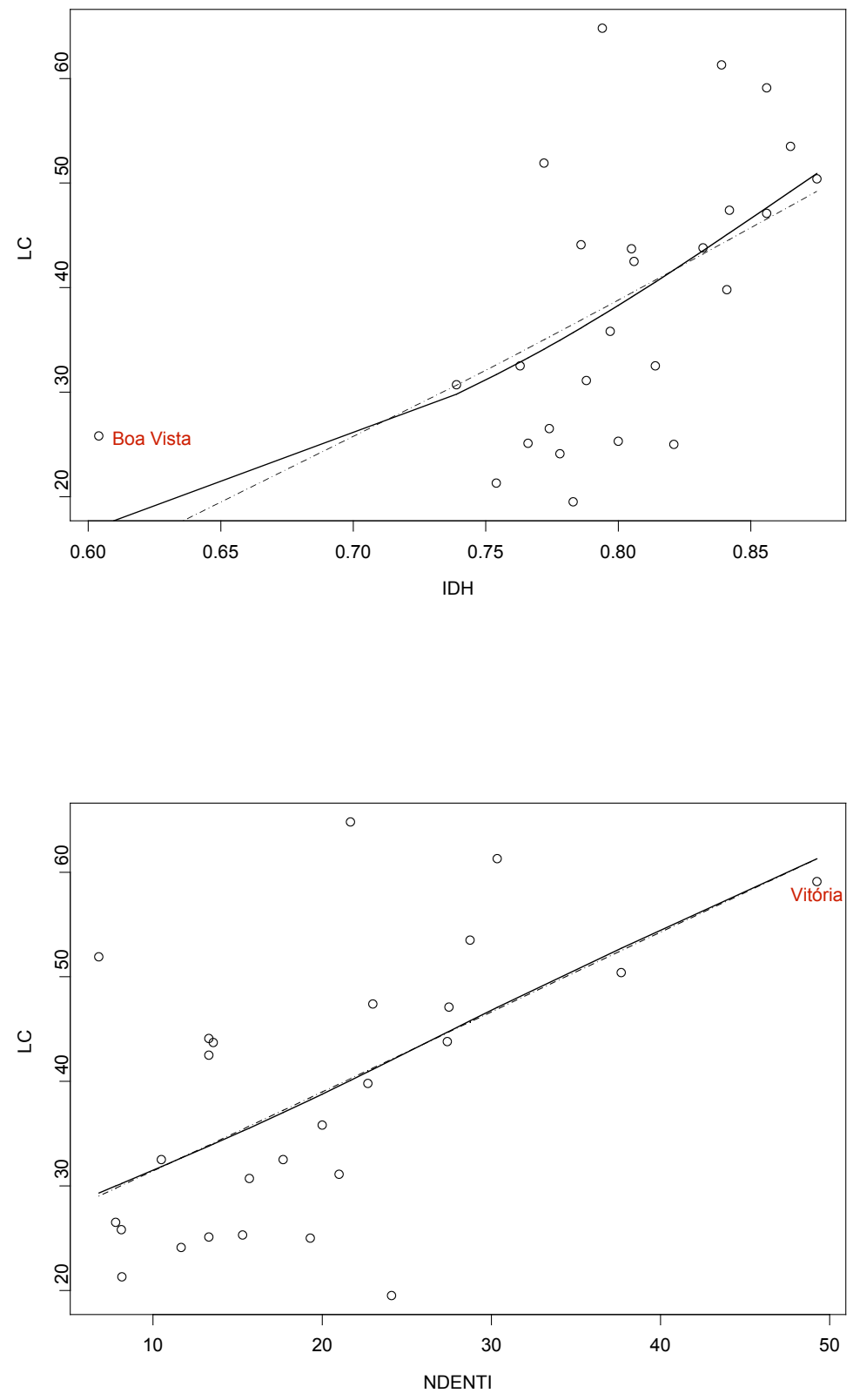


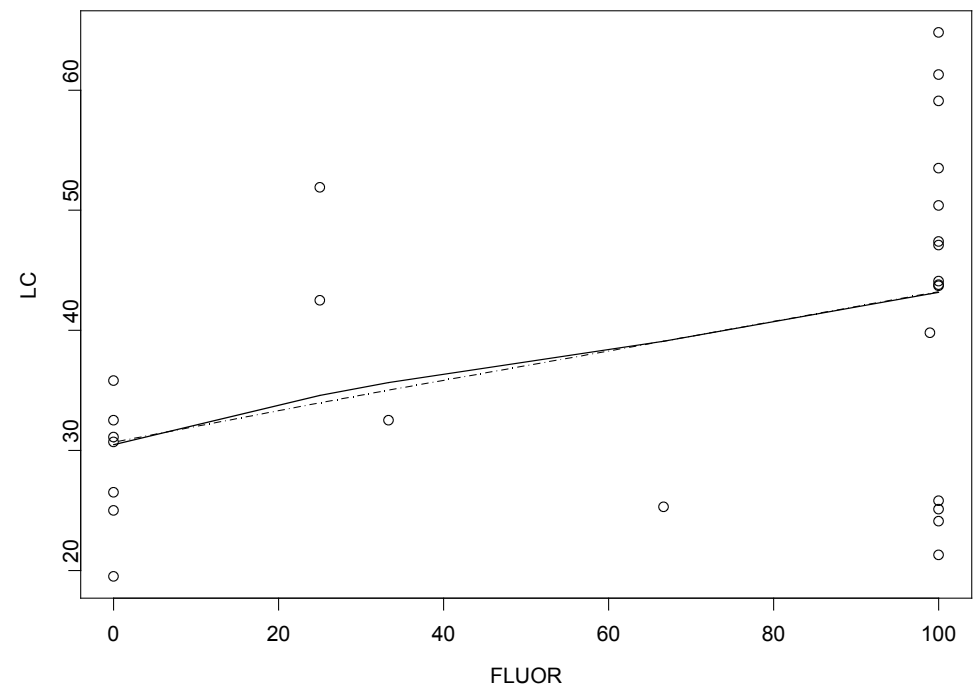


APÊNDICE E - Gráficos de dispersão entre percentual de redução no CPOD e cada uma das variáveis explicativas e respectivas curvas suavizadas pelo método cubic spline
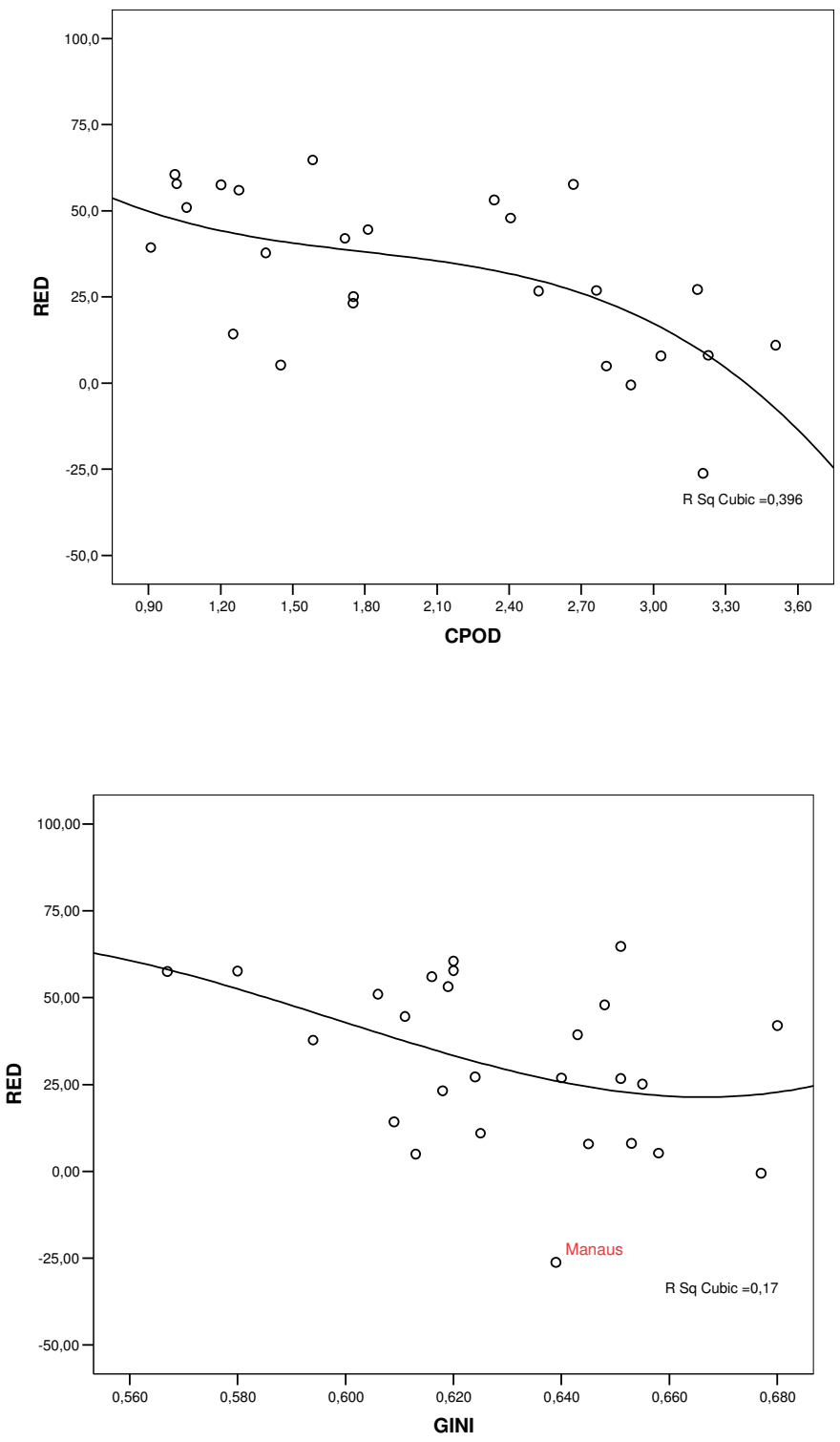


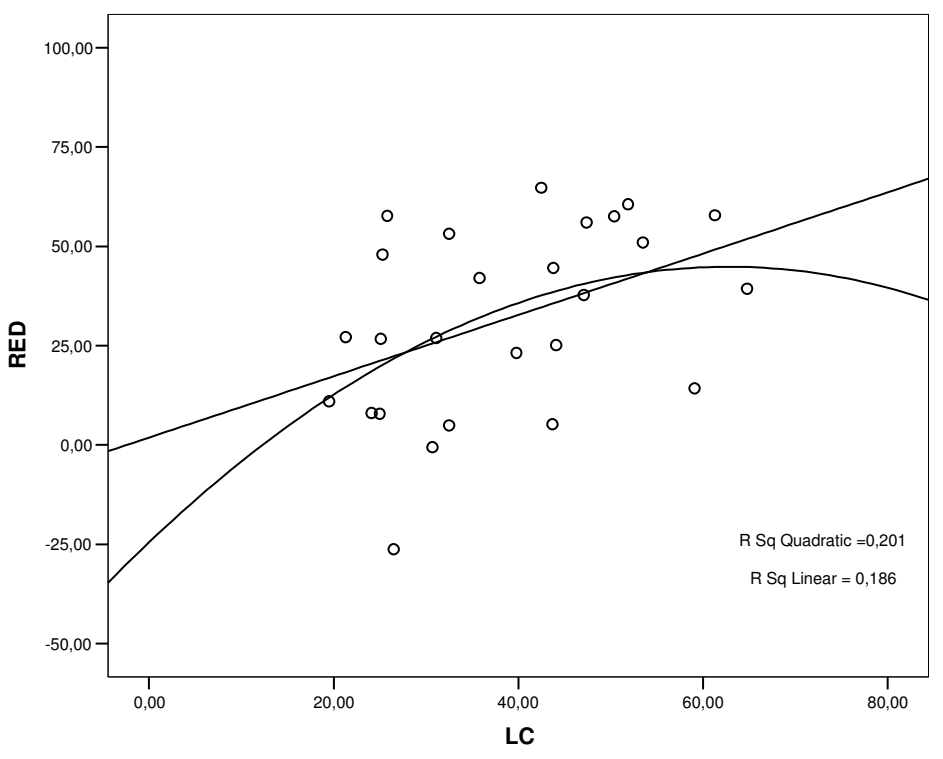

